\title{
Cannabinoid Transmission in the Basolateral Amygdala Modulates Fear Memory Formation via Functional Inputs to the Prelimbic Cortex
}

\author{
Huibing Tan, Nicole M. Lauzon, Stephanie F. Bishop, Ning Chi, Melanie Bechard, and Steven R. Laviolette \\ Department of Anatomy and Cell Biology, The Schulich School of Medicine and Dentistry, University of Western Ontario, London, Ontario N6A 5C1, \\ Canada
}

\begin{abstract}
The cannabinoid CB1 receptor system is critically involved in the control of associative fear memory formation within the amygdalaprefrontal cortical pathway. The $\mathrm{CB} 1$ receptor is found in high concentrations in brain structures that are critical for emotional processing, including the basolateral amygdala (BLA) and the prelimbic division (PLC) of the medial prefrontal cortex (mPFC). However, the precise role of $\mathrm{CB} 1$ receptor transmission within the BLA during the processing of fear memory is not fully understood. We examined the potential role of BLA CB1 receptor transmission during an olfactory fear-conditioning procedure in rats by pharmacologically modulating CB1 cannabinoid transmission directly within the BLA. We report that blockade of BLA CB1 receptor transmission prevents the acquisition of associative fear memory, while having no effect on the recall or consolidation of these memories. In contrast, intra-BLA activation of CB1 receptor transmission or blockade of endocannabinoid reuptake strongly potentiated the emotional salience of normally subthreshold fear-conditioning stimuli. In addition, pharmacological inactivation of the mPFC before intra-BLA CB1 activation blocked CB1-receptor-mediated potentiation of fear memory formation. In vivo single-unit electrophysiological recordings within the PLC revealed that modulation of BLA CB1 receptor transmission strongly influences neuronal activity within subpopulations of PLC neurons, with blockade of intra-BLA CB1 receptor transmission inhibiting spontaneous PLC neuronal activity and activation of CB1 receptors producing robust activation, in terms of neuronal firing frequency and bursting activity. Thus, cannabinoid transmission within the BLA strongly modulates the processing of associative fear memory via functional interactions with PLC neuronal populations.
\end{abstract}

\section{Introduction}

Considerable evidence implicates the basolateral nucleus of the basolateral amygdala (BLA) as being critical for the encoding of associative memories relevant to affective experiences (Aggleton, 2000; Rosenkranz and Grace, 2002, 2003). Furthermore, there is increasing clinical evidence linking disturbances in endocannabinoid transmission in the etiology of psychopathological disorders such as schizophrenia (Bangalore et al., 2008; Cohen et al., 2008; Schneider, 2008), which are characterized by profound disturbances in emotional regulation. Through interconnections with the medial prefrontal cortex (mPFC), fear-related associative memory can be encoded and expressed by neurons in both of these regions (Rosenkranz and Grace, 2002; Laviolette and Grace, 2006a,b). The cannabinoid CB1 receptor system is involved importantly in neural plasticity mechanisms related to the processing of emotionally salient learning and memory (Marsicano et al.,

\footnotetext{
Received Sept. 8, 2010; revised Feb. 15, 2011; accepted Feb. 15, 2011.

Author contributions: H.T. and S.R.L. designed research; H.T., N.M.L., S.F.B., N.C., M.B., and S.R.L. performed research; H.T., N.M.L., S.F.B., N.C., M.B., and S.R.L. analyzed data; H.T. wrote the paper.

This work supported by the Ontario Mental Health Foundation and a graduate fellowship to N.M.L. from the National Science and Engineering Research Council of Canada.

Correspondence should be addressed to Steven R. Laviolette, Department of Anatomy and Cell Biology, The Schulich School of Medicine and Dentistry, University of Western Ontario, London, Ontario, Canada N6A 5C1. E-mail: steven.laviolette@schulich.uwo.ca.

DOI:10.1523/JNEUROSCI.4718-10.2011

Copyright $\odot 2011$ the authors $\quad 0270-6474 / 11 / 315300-13 \$ 15.00 / 0$
}

2002; Laviolette and Grace, 2006a,b), and CB1 receptor expression is found in relatively high concentrations in both the BLA and mPFC (Tsou et al., 1998; McDonald and Mascagni, 2001). Within the BLA, CB1 receptors are found on inhibitory local GABAergic interneurons, but are absent in the adjacent central nucleus (Herkenham et al., 1990; Tsou et al., 1998; Katona et al., 2001). Functionally, activation of BLA CB1 receptors decreases feedforward inhibition via inhibitory interneurons, thereby increasing the activity of BLA projection neurons (Pistis et al., 2004). Given that both recall and extinction of conditioned fear memories are correlated with increased release of intra-BLA endocannabinoids (Marsicano et al., 2002), this suggests a critical role for intra-BLA CB1 transmission during the processing of emotionally salient information. However, how intra-BLA CB1 receptor transmission may modulate neuronal populations extrinsic to the amygdala in the context of fear memory formation is not presently understood.

Neuronal plasticity in the form of long-term potentiation (LTP) along the BLA $\rightarrow$ mPFC pathway is dependent on CB1 receptor transmission (Tan et al., 2010). Specifically, functional connectivity between the BLA and the prelimbic subdivision (PLC) of the mPFC is strongly modulated by CB1 receptor transmission in terms of behavioral encoding of fear-related memory and synaptic plasticity. Indeed, doses of systemic CB1 receptor antagonists that block in vivo LTP within the BLA $>$ PLC circuit are sufficient to block the acquisition of fear memories (Tan et al., 
2010). Given the known ability of intra-BLA CB1 receptor populations to modulate amygdala output neurons and evidence suggesting that integrated activity within both the PLC and BLA is required for fear memory plasticity (Tan et al., 2010), we hypothesized that blockade or activation of intra-BLA CB1 receptor populations may modulate the remote activity of neuronal populations within the PLC and similarly influence the formation of associative emotional memories. Accordingly, using an olfactory fear-conditioning paradigm, we performed a series of behavioral pharmacology studies combined with single-unit in vivo extracellular recordings of PLC neuronal populations to determine how $\mathrm{CB} 1$ receptor modulation within the BLA may modulate fear memory processing and remotely control neuronal activity within neurons of the PLC. Our findings suggest that CB1 receptor transmission directly within the BLA can strongly modulate the formation of emotionally salient memory via functional connectivity with neuronal populations in the PLC.

\section{Materials and Methods}

Surgical procedure. For intracranial microinfusion studies in the BLA or PLC subdivision of the mPFC, male Sprague Dawley rats (Charles River, $350-400 \mathrm{~g}$ at the start of experiments) were anesthetized with a ketamine $(80 \mathrm{mg} / \mathrm{ml})$-xylazine $(6 \mathrm{mg} / \mathrm{ml})$ mixture and placed into a stereotaxic device. Stainless steel guide cannulae (22 gauge; Plastics One) were bilaterally implanted using the following stereotaxic coordinates (in $\mathrm{mm}$ ): for the PLC ( $15^{\circ}$ angle): from bregma, anteroposterior (AP), +2.9; lateral (L), \pm 1.9 ; from the dural surface, ventral $(\mathrm{V}),-3.0$; for the BLA $\left(0^{\circ}\right.$ angle): from bregma, AP, $-3.0 ; \mathrm{L}, \pm 5.0$; from the dural surface, $\mathrm{V},-7.4$. Guide cannulae were secured with jeweler's screws and dental acrylic. At the conclusion of the experiments, rats were deeply anesthetized and transcardially perfused with isotonic saline followed by $10 \%$ formalin. Brain sections were stained with cresyl violet, and PLC or BLA injector placements were verified with light microscopy according to the anatomical boundaries defined by Paxinos and Watson (1997). Rats found to have cannula placements outside the boundaries of the target region were excluded from analysis. For in vivo electrophysiological recording experiments, male Sprague Dawley rats (300-350 g) were anesthetized with urethane (Sigma; $1.4-1.5 \mathrm{mg} / \mathrm{kg}$, i.p.) and placed in a stereotaxic device. Body temperature was monitored with a rectal temperature probe and maintained at $\sim 37^{\circ} \mathrm{C}$. Incisions were made in the scalp to expose the skull, burr holes were drilled, and the dura overlying the BLA and PLC was removed. Stereotaxic coordinates for these electrophysiological studies were determined using the stereotaxic atlas of Paxinos and Watson (2005) with the following coordinates from bregma (in mm): BLA: AP,$-3.0 ; \mathrm{L}, \pm 5.0 ; \mathrm{V},-7.4$ from the dural surface; PLC: AP , +3.0 rostral; $\mathrm{L}, \pm 0.8-1.0 ; \mathrm{V},-3.4$ from the dural surface.

In vivo electrophysiology: single-unit neuronal recordings in the mPFC. For all single-unit extracellular recordings, conventional extracellular recording methods were used as described previously (Laviolette et al., 2005; Laviolette and Grace, 2006a). Electrodes were pulled from borosilicate glass with an average impedance between 6 and $8 \mathrm{M} \Omega$. Microelectrodes were filled with a $2 \%$ Pontamine Sky Blue solution and slowly lowered into the PLC with coordinates described above. Extracellular signals were amplified using a MultiClamp 700B amplifier (Molecular Devices) and recorded through a Digidata 1440A acquisition system (Molecular Devices) using pClamp 10 software. Extracellular recordings were typically filtered at $1 \mathrm{kHz}$ and sampled at $5 \mathrm{kHz}$. Before electrode preparation in the PLC, rats were implanted with a unilateral guide cannula aimed at the BLA, using the same surgical methods and procedures outlined above in Surgical procedure. Once the recording and stimulating electrodes were stereotactically positioned, anesthetized rats were left undisturbed for at least $45 \mathrm{~min}$ before beginning the neuronal recording experiments. The microelectrode was then slowly lowered into the PLC subdivision of the MPFC, and once a neuron within the PLC was stably isolated for recording, baseline spontaneous activity was recorded for at least 20 min before the microinfusion of any drugs into the BLA. Drugs were then microinfused into the BLA with a microinjector in a volume of
$0.5 \mu \mathrm{l}$, slowly over $1 \mathrm{~min}$. During this time, intra-mPFC neuronal recordings were continuous. After microinfusion, intra-PLC neuronal recordings continued for at least $30 \mathrm{~min}$, depending on the stability of the extracellular recording. For all experiments involving intra-BLA drug microinfusions, only a single neuron per rat was recorded for each experiment. For statistical analysis of MPFC neuronal firing frequency before and after BLA microinfusions of either AM251 or WIN 55,212-2, we compared the $10 \mathrm{~min}$ firing epoch immediately before the microinfusion and the following $10 \mathrm{~min}$ postinfusion recording epochs.

Bursting analysis. Analysis of bursting parameters for in vivo extracellular recordings of $\mathrm{MPFC}$ neurons has been described previously (Laviolette et al., 2005; Laviolette and Grace, 2006a). Using previously established criteria based on an analysis of baseline recordings of spontaneously active mPFC neurons, a bursting event was defined as the occurrence of two or more spikes with an interspike interval (ISI) of $<45$ $\mathrm{ms}$. We hypothesized that the spiking of PLC neurons could be described by two separate spiking modes, regular spiking and bursting, that produced a characteristic ISI distribution that could be modeled by an inverse Gaussian probability density (IGPD) function (Barbieri et al., 2001). We therefore fit our collective baseline ISI histogram with a sum of two IGPDs as follows:

$$
P\left(w_{i} \mid \mu_{\mathrm{b}}, \gamma_{\mathrm{b}}, \mu_{\mathrm{r}}, \gamma_{\mathrm{r}}\right)=f\left(w_{i} \mid \mu_{\mathrm{r}}, \gamma_{\mathrm{r}}\right) \mid f\left(w_{i} \mid \mu_{\mathrm{b}}, \gamma_{\mathrm{b}}\right),
$$

where

$$
f\left(w_{i} \mid \mu, \lambda\right)=\left(\frac{\lambda}{2 \pi w_{i}^{3}}\right)^{\frac{1}{2}} \exp \left\{-\frac{\lambda\left(w_{i}-\mu\right)^{2}}{2 \mu^{2} w_{i}}\right\},
$$

and $w_{i}$ is an ISI in the distribution; $\mu_{\mathrm{r}}$ and $\mu_{\mathrm{b}}$ are the expected values of the regular-mode and burst-mode ISI, respectively; and $\mu^{3} \lambda^{-1}$ describes the variance of each distribution. Fit optimization was performed in Matlab (MathWorks) using a least-squares algorithm with the following four free parameters: $\mu_{\mathrm{r}}, \lambda_{\mathrm{r}}, \mu_{\mathrm{b}}$, and $\lambda_{\mathrm{b}}$. Analysis was performed on both the percentage of spiking events that occurred in the form of a burst and the number of individual spikes within each burst event. We have reported previously that mPFC neuronal bursting is not an epiphenomenon of firing frequency because no significant correlation exists between cortical neuron firing frequency and percentage of spikes occurring within burst events (Laviolette et al., 2005).

Intra-BLA and intra-PLC drug administration. For intra-BLA and intra-PLC bilateral microinfusions, drugs were administered through a 28 gauge microinfusion injector (Plastics One) via the surgically implanted guide cannulae. For intra-BLA cannabinoid antagonist, agonist, and reuptake inhibitor behavioral conditioning experiments, AM251 (2.5-500 ng/0.5 $\mu$ l; Sigma), WIN 55,212-2 mesylate salt (5-500 ng/0.5 $\mu$ l; Tocris Bioscience), or AM404 (5-50 ng/0.5 $\mu$; Tocris Bioscience) was dissolved in DMSO and then diluted in PBS for a final 1\% DMSO in PBS vehicle solution ( $\mathrm{pH}$ adjusted to 7.4). Vehicle control experiments used the same DMSO/PBS solution for microinfusions. Drug or vehicle solutions were microinfused bilaterally into the BLA immediately before the start of the fear-conditioning procedure. For experiments involving intra-mPFC microinfusions of muscimol (500 ng/0.5 $\mu$ l; Sigma)induced pharmacological inactivation pretreatment before intra-BLA cannabinoid activation (WIN 55,212-2), intra-PLC microinfusions were performed immediately before bilateral intra-BLA microinfusions of WIN 55,212-2 (500 ng/0.5 $\mu \mathrm{l})$. To verify the pharmacological specificity of WIN 55,212-2-mediated potentiation of emotional memory encoding, a separate control group received bilateral intra-BLA coadministration of the highest behaviorally effective doses of WIN 55,212-2 (500 $\mathrm{ng} / 0.5 \mu \mathrm{l})$ with AM251 (500 ng/0.5 $\mu \mathrm{l})$ before conditioning sessions with the subthreshold footshock-conditioning stimulus $(0.4 \mathrm{~mA})$.

Histology. At the conclusion of experiments, extracellular recording sites in the PLC, electrical stimulation sites in the BLA, and bilateral intra-PLC or intra-BLA guide cannula placements were all verified histologically. For electrophysiological studies, the electrode position was marked with an iontophoretic deposit of Pontamine Sky Blue $(-20 \mu \mathrm{A}$; continuous negative current for 10-15 min), after which rats were transcardially perfused with $10 \%$ formalin in $0.05 \%$ PBS. The brains were 
placed into $25 \%$ sucrose in $10 \%$ formalin before sectioning and mounting. The mounted sections were passed through graded alcohols and distilled water, stained with neutral red for $2-5 \mathrm{~min}$, and then rinsed in double-distilled water. Recording sites were identified with Pontamine Sky Blue spots. The stimulation site was determined from the ventralmost point of the stimulating electrode track identified under light microscopy. For the analysis of bilateral intra-BLA or intra-PLC microinfusion studies, rats were deeply anesthetized and perfused with a $10 \%$ formalin solution. Brains were removed and fixed in $10 \%$ formalin solution for a minimum of $24 \mathrm{~h}$. Brains were cryoprotected with $25 \%$ sucrose in $0.1 \mathrm{M}$ phosphate buffer, frozen, and sectioned with a cryostat at $40 \mu \mathrm{m}$. Mounted sections were then stained with cresyl violet. Bilateral PLC or BLA microinfusion locations were determined by the location of the injector tip.

Statistics. Behavioral and/or electrophysiological data were analyzed with one- or two-way ANOVA or Student's $t$ tests where appropriate. Post hoc analyses were performed with Fisher's LSD tests or NewmanKeuls tests.

Olfactory fear-conditioning procedure. All behavioral pharmacological experiments were performed on separate groups of rats for each dose and treatment group. Rats were taken from their home cages, were given sham vehicle microinfusions into the BLA and/or PLC, and were habituated for $30 \mathrm{~min}$ in a ventilated conditioning chamber with an electric grid floor inside a sound-attenuated room. Olfactory fear conditioning took place in one of two distinct environments, counterbalanced within groups: "shock" environment A was a $30 \times 30$ inch Plexiglas box with black stripes on a white background and a metallic grid shock floor, whereas shock environment B was a $30 \times 30$ inch Plexiglas box with black dots on a white background with a grid shock floor. Testing $24 \mathrm{~h}$ later took place in one of two alternate environments, in which rats had not previously received electric shock, counterbalanced within groups: test environment A had walls with black dots and a gray Plexiglas floor, whereas test environment $B$ had walls with black and white stripes and a gray Plexiglas floor. On day 1 (habituation phase), rats were habituated to a random combination of shock environment $\mathrm{A}$ or $\mathrm{B}$ and test environment A or B in a counterbalanced order for $30 \mathrm{~min}$ in each environment. On day 2 (conditioning phase), rats were returned to the conditioning room and placed in the previously assigned shock environment. During the conditioning phase, one of the odors (almond or peppermint) was presented to the rat for $19 \mathrm{~s}$, and a footshock was then delivered $(0.4$ or 0.8 $\mathrm{mA})$ for $1 \mathrm{~s}$. These two levels of footshock $(0.4$ and $0.8 \mathrm{~mA})$ corresponded to subthreshold and suprathreshold levels of fear-conditioning stimuli, with the lower level $(0.4 \mathrm{~mA})$ not producing an associative freezing response at testing and the higher level producing robust associative freezing upon testing (Laviolette and Grace, 2006a; Lauzon et al., 2009). One hundred twenty seconds later, the alternate odor was presented for $20 \mathrm{~s}$ (CS-) in the absence of footshock. This cycle was repeated five times. On the following day (test phase), rats were returned to the test room and placed in the previously assigned test environment. Before odor presentation, the rat was allowed to explore the environment for $1 \mathrm{~min}$, during which time baseline levels of freezing and exploratory behavior were observed. Odors ( $\mathrm{CS}+$ or $\mathrm{CS}-$ ) were then presented for 5 min each to the rat in a counterbalanced order, and the amount of time freezing was recorded. Freezing was defined as complete immobility with the exception of respiratory-related movement. We also analyzed exploratory behavior in response to presentations of CS + or CS- odors, as described previously (Rosenkranz and Grace, 2003; Laviolette et al., 2005; Lauzon et al., 2009). Exploratory behavior was scored as follows, with a score assigned for each minute of the 5 min during the CS + or CS - odor presentations: 0 , no locomotion; 1 , ambulation across one side of the testing chamber; 2 , ambulation across two sides; 3 , exploration of the full perimeter of the testing chamber; and 4, exploration of the center and entire perimeter of the test chamber. Freezing behavior and exploratory behavior scores were recorded for each rat during the testing phase. Experimental groups received intra-BLA microinfusions of AM251 or WIN 55,212-2 either immediately before the conditioning phase (memory acquisition challenge), immediately after the conditioning phase (consolidation challenge), or immediately before the testing phase (expression/recall challenge).
Footshock sensitivity analyses. To determine whether behaviorally effective doses of intra-BLA cannabinoid pharmacological manipulations (AM251 or WIN 55,212-2) may have produced unconditioned alterations in sensitivity to footshock (e.g., pronociceptive or antinociceptive effects), behavioral responses to these intra-BLA manipulations were carefully monitored before and after drug administration, as described previously (Laviolette and Grace, 2006a; Lauzon et al., 2009). For intraBLA behavioral conditioning experiments, we performed separate control experiments, wherein rats received either bilateral intra-BLA vehicle (control) or the highest behaviorally effective doses of the $\mathrm{CB} 1$ antagonist (AM251; $500 \mathrm{ng} / 0.5 \mu \mathrm{l}$ ) or agonist (WIN 55,212-2; $500 \mathrm{ng} / 0.5 \mu \mathrm{l}$ ) and were placed in a neutral test environment with a footshock grid floor. In separate experiments, we tested a battery of sensitivity measures using either the behaviorally subthreshold or suprathreshold footshock levels (0.4 and $0.8 \mathrm{~mA}$, respectively) presented a total of five times for $1 \mathrm{~s}$ durations, similar to the time course of footshock presentations in the olfactory fear-conditioning procedure, but with the absence of any olfactory cue delivery. Immediately after each footshock presentation, we measured sensitivity to footshock over five separate variables: (1) percentage of freezing behavior for the $20 \mathrm{~s}$ period immediately after the footshock, (2) number of jumps in response to footshock, (3) amount of defecation (in grams) during the entire footshock testing session, (4) number of "rearing" events during the testing period, and (5) an exploratory behavior score for the $1 \mathrm{~min}$ period after footshock, as described above in Olfactory fear-conditioning procedure. These behavioral indices of footshock sensitivity have been identified as reliable indicators of fear reactivity to the presentation of a footshock stimulus (Antoniadis and McDonald, 1999; Lauzon et al., 2009).

\section{Results}

\section{Blockade of $\mathrm{CB} 1$ receptors in the BLA prevents the} acquisition of olfactory fear memory

For experimental groups receiving intra-BLA AM251, $24 \mathrm{~h}$ after the completion of fear conditioning, we measured the percentage of time rats spent freezing in response to the presentation of the CS + or CS - odors. Two-way ANOVA revealed a significant interaction between group and treatment $\left(F_{(4,51)}=7.58 ; p<\right.$ $0.001)$ on times spent freezing to the CS + versus CS - odor presentations (Fig. 1A). Post hoc analysis revealed that whereas vehicle control $(n=6)$ and rats receiving a dose of $2.5 \mathrm{ng}$ of AM251 $(n=7)$ displayed significantly greater time freezing specifically in response to the presentation of the CS+ odor than to the CSpresentations $(p<0.01)$, rats receiving higher doses of intraBLA AM251 (25 ng, $n=6$; $50 \mathrm{ng}, n=7$; and $500 \mathrm{ng}, n=7$ ) displayed no differences in percentage of time spent freezing to the $\mathrm{CS}+$ versus $\mathrm{CS}-$ odor presentations at testing $(p>0.05)$ (Fig. 1A). Furthermore, post hoc analysis revealed that percentages of time spent freezing to CS+ presentations were significantly lower in groups receiving the higher doses of intra-BLA AM251 (50-500 ng), relative to vehicle controls or rats receiving the lower dose of AM251 (2.5 ng). Thus, blockade of CB1 receptor transmission within the BLA dose-dependently blocked the acquisition of olfactory fear memories. Comparing exploratory behavior scores across groups in response to CS + or CS - presentations revealed a significant main effect of treatment on exploratory behavior $\left(F_{(4,51)}=4.1 ; p<0.01\right)$ during testing (Fig. $1 B)$. Post hoc analysis revealed that whereas both vehicle control $(n=6)$ and the lowest dose of $2.5 \mathrm{ng}$ of AM251 $(n=7)$ displayed significantly lower exploratory behavior in response to the presentation of the CS + relative to $\mathrm{CS}-(p<0.05)$, this effect was absent in the rats receiving the higher doses of intra-BLA AM251 $(25,50$, and $500 \mathrm{ng} / 0.5 \mu \mathrm{l})$. Thus, intra-BLA blockade of CB1 transmission dose-dependently blocks associative suppression of exploratory behavior in response to CS + or CS - presentations. To determine whether intra-BLA CB1 receptor 

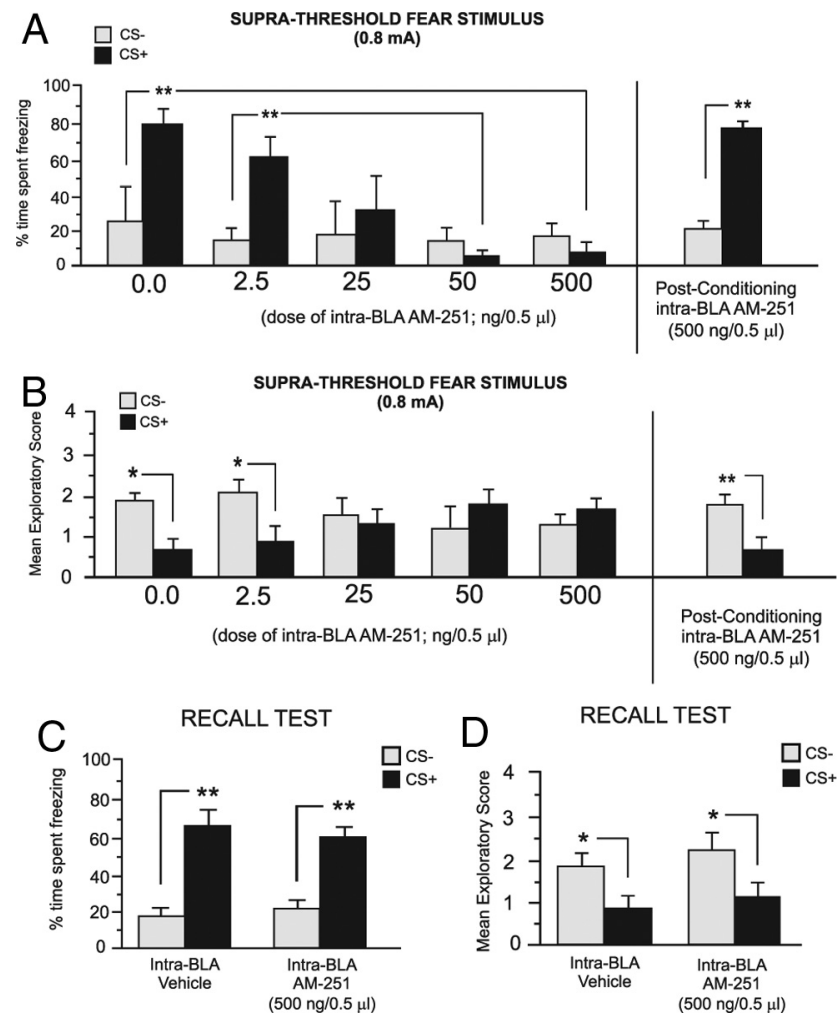

Figure 1. Effects of intra-BLA AM251 microinfusions on associative olfactory fear conditioning. A, Bilateral microinfusions of the CB1 antagonist AM251 $(2.5 \mathrm{ng} / 0.5 \mu \mathrm{l}, n=7$; $25 \mathrm{ng} / 0.5 \mu \mathrm{l}, n=6 ; 50 \mathrm{ng} / 0.5 \mu \mathrm{l}, n=7$; and $500 \mathrm{ng} / 0.5 \mu \mathrm{l}, n=7$ ) dose-dependently blocks the acquisition of associative olfactory fear memory to a $\mathrm{CS}+$ cue paired with 0.8 $\mathrm{mA}$ footshock. However, the highest behaviorally effective dose of intra-BLA AM251 (500 $\mathrm{ng} / 0.5 \mu \mathrm{l}$ ) fails to block the recall of olfactory fear memory when administered immediately after training, during the consolidation phase (right). B, Bilateral microinfusions of the $\mathrm{CB} 1$ antagonist AM251 dose-dependently blocks conditioned exploratory behavior suppression during $\mathrm{CS}+$ or $\mathrm{CS}$ - presentations during testing. However, the highest behaviorally effective dose of intra-BLA AM251 $(500 \mathrm{ng} / 0.5 \mu \mathrm{l})$ fails to block the recall of olfactory fear memory in terms of conditioned exploratory behavior when administered immediately after training, during the consolidation phase (right). C, D, Bilateral intraBLA microinfusions of the highest effective dose of AM251 ( $500 \mathrm{ng} / 0.5 \mu \mathrm{l} ; n=7)$ immediately before testing (expression phase) had no effect on the expression of associative conditioned fear $(\boldsymbol{C})$ or on conditioned suppression of exploratory behavior measured during the expression test (D). For this and all subsequent figures, ${ }^{*} p<0.05 ;{ }^{* *} p<0.01$.

blockade may modulate the consolidation of olfactory fear memory, an additional control experiment was performed in which rats $(n=8)$ received microinfusions of the highest behaviorally effective dose of intra-BLA AM251 (500 ng/0.5 $\mu l)$ immediately after the completion of the training phase (consolidation challenge; see above, Materials and Methods, Olfactory fear-conditioning procedure). Comparing freezing behavior in response to CS+ versus CS - presentations revealed significantly greater freezing behavior specifically in response to CS + than to CS - presentations $\left(t_{(7)}=13.5 ; p<\right.$ 0.01 ) (Fig. $1 A$, right). Similarly, comparing exploratory behaviors revealed significantly greater conditioned suppression of exploratory behavior specifically in response to CS + presentations than to CS - presentations $\left(t_{(7)}=3.48 ; p<0.01\right)$ (Fig. $1 B$, right). Thus, blockade of intra-BLA CB1 transmission during the consolidation phase of olfactory fear learning does not appear to influence the later expression of olfactory fear memory.

\section{CB1 receptor blockade in the BLA does not influence the recall of previously acquired fear memory}

To determine whether intra-BLA CB1 receptor blockade would similarly block the expression (recall) of associative fear conditioning and to control for possible state-dependent effects of the BLA CB1 receptor blockade, we ran an additional experiment wherein rats received the highest behaviorally effective dose of intra-BLA AM251 (500 ng/0.5 $\mu \mathrm{l} ; n=7)$ or vehicle $(n=7)$ immediately before the testing phase (Fig. $1 C, D$ ). Rats tested in the presence of intra-BLA AM251 (500 ng) displayed no difference in freezing in response to $\mathrm{CS}+$ or $\mathrm{CS}-$ presentations relative to vehicle controls as both the control group $\left(t_{(6)}=5.3 ; p<0.01\right)$ and the intra-BLA AM251 group $\left(t_{(6)}=6.2 ; p<0.01\right)$ displayed significantly greater amounts of freezing to the $\mathrm{CS}+$ presentation than to CS - presentation (Fig. $1 C$ ). Similarly, both the vehicle group $\left(t_{(6)}=1.69 ; p<0.05\right)$ and the intra-BLA AM251 group $\left.t_{(6)}=1.8 ; p<0.05\right)$ showed significantly less exploratory behavior in response to $\mathrm{CS}+$ presentations relative to CSpresentations (Fig. 1D), demonstrating that the observed block in olfactory associative learning with an effective dose of the intra-BLA CB1 antagonist was not caused by any state dependency effects and did not interfere with the expression (recall) of the previously acquired fear memory.

\section{Activation of $\mathrm{CB} 1$ receptors in the BLA potentiates fear memory acquisition}

For experimental groups receiving intra-BLA WIN 55,212-2, $24 \mathrm{~h}$ after the completion of fear conditioning with a subthreshold footshock (0.4 mA)-conditioning stimulus (see Materials and Methods), we measured the percentage of time rats spent freezing in response to the presentation of the CS + or CS - odors. Statistical analysis revealed a significant interaction between group and treatment $\left(F_{(3,41)}=10.2 ; p<0.001\right)$ on times spent freezing to the CS+ compared with the CS - odor presentations (Fig. 2A). Post hoc analyses revealed that whereas vehicle control $(n=6)$ and rats receiving a lower dose of 5 ng of intra-BLA WIN 55,212-2 $(n=7)$ displayed no significant differences in times spent freezing in response to $\mathrm{CS}+$ or CS - presentations $(p>0.05)$, groups receiving higher doses of intra-BLA WIN 55,212-2 (50 ng/0.5 $\mu \mathrm{l}$, $n=8$; or $500 \mathrm{ng} / 0.5 \mu \mathrm{l}, n=7$, respectively) displayed significantly greater times freezing, specifically during CS+ presentations $(p<0.01)$ (Fig. $2 A)$, relative to CS - presentations. Furthermore, comparing times spent freezing with CS + presentations across groups revealed significantly greater CS + freezing in the group receiving the higher doses of WIN 55,212-2 (50-500 $\mathrm{ng} / 0.5 \mu \mathrm{l}$ ) than in vehicle controls or the group receiving the lower dose $(p<0.01)$. Thus, activation of CB1 receptor transmission within the BLA dose-dependently potentiates the ability of a subthreshold footshock stimulus $(0.4 \mathrm{~mA})$ to produce an associative fear memory.

Comparing exploratory behavior scores across groups in response to CS + or CS - presentations revealed a significant main effect of treatment on exploratory behavior scores $\left(F_{(3,41)}=3.85\right.$; $p<0.05$ ) (Fig. 2 B). Post hoc analysis revealed that whereas both vehicle control $(n=6)$ and the lower dose group ( $5 \mathrm{ng} / 0.5 \mu \mathrm{l} ; n=$ 7 ) did not display an associative suppression of exploratory behavior in response to CS + or CS - presentations $(p>0.05)$, the groups receiving the higher doses of intra-BLA WIN 55,212-2 (50-500 ng/0.5 $\mu \mathrm{l}$ ) demonstrated significant suppression of exploratory behavior specifically in response to the $\mathrm{CS}+$, relative to $\mathrm{CS}-$ presentations $(p<0.01)$. Furthermore, comparing exploratory behavior suppression during CS+ presentations across groups revealed significantly greater CS + exploratory suppres- 

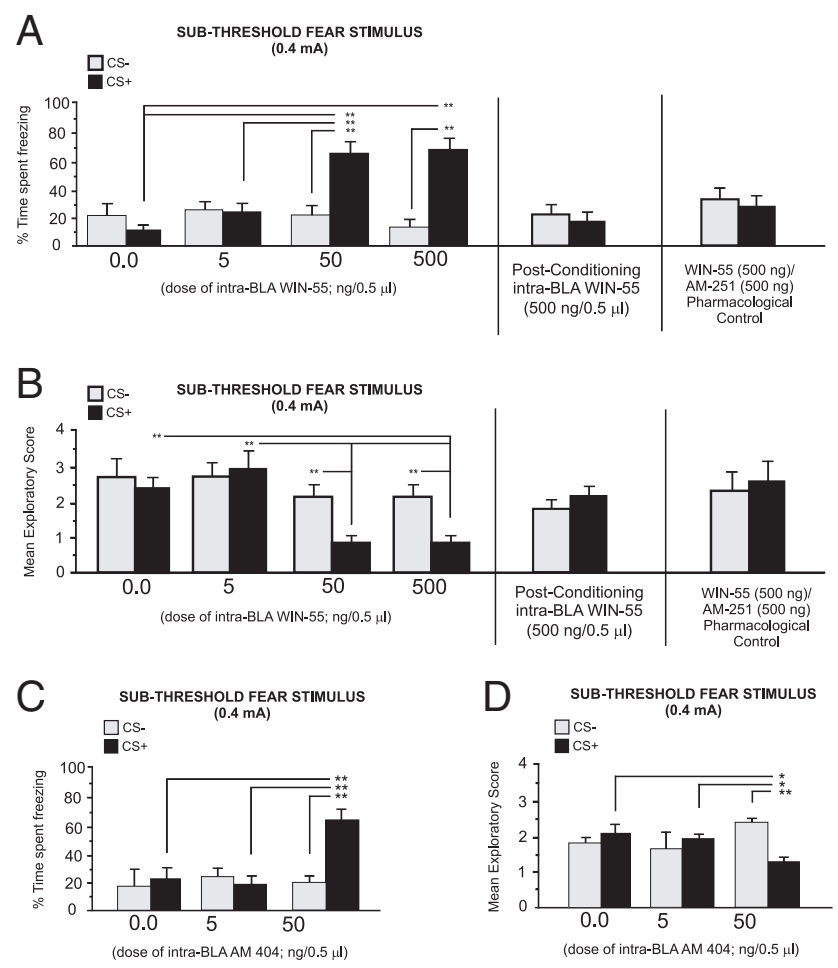

Figure 2. Effects of intra-BLA WIN 55,212-2 microinfusions on associative olfactory fear conditioning. $A$, Bilateral microinfusions of the CB1 agonist WIN 55,212-2 ( $5 \mathrm{ng} / 0.5 \mu \mathrm{l}, n=7$; $50 \mathrm{ng} / 0.5 \mu \mathrm{l}, n=7$; or $500 \mathrm{ng} / 0.5 \mu \mathrm{l}, n=7$ ) dose-dependently potentiates fear memory acquisition during conditioning to a subthreshold footshock level ( $0.4 \mathrm{~mA}$; see Materials and Methods). However, intra-BLA WIN 55,212-2 (500 ng/0.5 $\mu$ l) microinfusions immediately after conditioning (see Materials and Methods) fail to potentiate fear memory acquisition (right). Coadministration of the highest effective dose of WIN 55,212-2 (500 ng/0.5 $\mu$ l) with the highest effective dose of AM251 ( $500 \mathrm{ng} / 0.5 \mu \mathrm{l} ; n=7$ ) blocks (B1 receptor agonist-induced potentiation of fear memory acquisition (far right). $\boldsymbol{B}$, Bilateral microinfusions of WIN 55,212-2 $(5-500 \mathrm{ng} / 0.5 \mu \mathrm{l})$ similarly produced a dose-dependent potentiation of conditioned exploratory behavior suppression after $C S+$ presentations. However, intra-BLA WIN 55,212-2 (500 $\mathrm{ng} / 0.5 \mu \mathrm{l}$ ) microinfusions immediately after conditioning (see Materials and Methods) fail to potentiate conditioned suppression of exploratory behavior (right). Again, this effect of intra-BLA WIN 55,212-2 (500 ng/ $0.5 \mu \mathrm{l})$ is blocked by coadministration with the highest effective dose of AM251 ( $500 \mathrm{ng} / 0.5 \mu \mathrm{l}$; far right). C, $\boldsymbol{D}$, Intra-BLA microinfusions of the endocannabinoid reuptake inhibitor AM404 dose-dependently potentiates fear memory acquisition ( $5 \mathrm{ng} / 0.5 \mu \mathrm{l}, n=7 ; 50 \mathrm{ng} / 0.5 \mu \mathrm{l}, n=8$ ) to a subthreshold level of footshock, relative to vehicle controls $(n=7)(\boldsymbol{C})$, and potentiates conditioned suppression of exploratory behavior after $\mathrm{C}+$ presentations $(\boldsymbol{D})$.

sion in the group receiving the highest doses of WIN 55,212-2 $(50-500 \mathrm{ng} / 0.5 \mu \mathrm{l})$ relative to vehicle controls or the group receiving the lower dose $(p<0.01)$ Thus, direct activation of CB1 receptors within the BLA dose-dependently potentiates the acquisition of fear memory during conditioning to normally subthreshold fear-related stimuli.

To determine whether intra-BLA CB1 receptor activation may modulate the consolidation of olfactory fear memory during conditioning to a subthreshold footshock stimulus $(0.4 \mathrm{~mA})$, an additional control experiment was performed in which rats $(n=$ 7) received microinfusions of the highest behaviorally effective dose of intra-BLA WIN 55,212-2 (500 ng/0.5 $\mu$ l) immediately after the completion of the training phase (consolidation challenge; see Materials and Methods, Olfactory fear-conditioning procedure). Comparing freezing behavior in response to CS+ versus CS - presentations revealed no significant differences in freezing behavior in response to CS + versus CS - presentations $\left(t_{(6)}=1.07 ; p>0.05\right)$ (Fig. $2 A$, right). Similarly, comparing exploratory behaviors revealed no significant difference in conditioned suppression of exploratory behavior in response to CS+ presentations versus CS - presentations $\left(t_{(6)}=0.4 ; p>0.05\right)$ (Fig. $2 B$, right). Thus, activation of intra-BLA CB1 transmission during the consolidation phase of olfactory fear learning does not appear to influence the later expression of olfactory fear memory. To determine the pharmacological specificity for the effects of intra-BLA WIN 55,212-2, we performed a separate control experiment wherein rats received coadministration of the highest behaviorally effective dose of WIN 55,212-2 (500 ng/0.5 $\mu \mathrm{l})$ with AM251 $(500 \mathrm{ng} / 0.5 \mu \mathrm{l})$ before conditioning sessions with the subthreshold footshock-conditioning stimulus $(0.4 \mathrm{~mA})$. Analysis of freezing behavior revealed no associative freezing behavior in response to CS + or CS - presentations $\left(t_{(6)}=0.88 ; p>0.05\right)$ (Fig. $2 \mathrm{~A}$, far right), demonstrating pharmacological specificity for the effects of intra-BLA CB1 receptor activation on associative freezing behavior. In addition, no associative suppression of exploratory behavior was demonstrated in response to CS+ or CS - stimulus presentations $\left(t_{(6)}=1.22 ; p>0.05\right.$ ) (Fig. $2 B$, far right), demonstrating pharmacological specificity for the effects of intra-BLA CB1 receptor activation on associative suppression of exploratory behavior.

\section{Blockade of endocannabinoid reuptake in the BLA potentiates fear memory acquisition}

Given that direct intra-BLA CB1 receptor activation potentiates subthreshold emotional fear memory acquisition (Fig. $2 A, B$ ), we next ran a separate control experiment to determine whether potentiating endocannabinoid tone within the BLA by inhibiting the reuptake of the endocannabinoid, anandamide, would similarly potentiate the acquisition of fear-conditioning memory to a subthreshold footshock stimulus. We thus performed bilateral intra-BLA microinfusions of the selective endocannabinoid reuptake inhibitor AM404 before conditioning with a subthreshold level of footshock (0.4 mA) (see Materials and Methods). Statistical analysis revealed a significant interaction between group and treatment $\left(F_{(2,43)}=11.4 ; p<0.001\right)$ on times spent freezing to the CS+ versus CS - odor presentations (Fig. 2C). Post hoc analyses revealed that whereas vehicle control $(n=6)$ and rats receiving a lower dose of $5 \mathrm{ng}$ intra-BLA AM404 $(n=7)$ displayed no significant differences in times spent freezing in response to CS+ or CS - presentations $(p>0.05)$, groups receiving a higher doses of intra-BLA AM404 (50 ng/0.5 $\mu \mathrm{l}, n=8)$ displayed significantly greater times freezing, specifically during CS+ presentations $(p<0.01)$ (Fig. $2 C)$, relative to CS - presentations. Furthermore, comparing times spent freezing with $\mathrm{CS}+$ presentations across groups revealed significantly greater associative CS+ freezing in the group receiving the higher dose of AM404 (50 $\mathrm{ng} / 0.5 \mu \mathrm{l})$ than the vehicle control or the group receiving the lower dose $(p<0.01)$.

Comparing exploratory behavior scores across groups in response to CS + or CS - presentations revealed a significant main effect of treatment on exploratory behavior scores $\left(F_{(1,43)}=3.85\right.$; $p<0.05)$ (Fig. 2D). Post hoc analysis revealed that whereas both vehicle control $(n=6)$ and the lower dose AM404 group (5 $\mathrm{ng} / 0.5 \mu \mathrm{l} ; n=7$ ) did not display an associative suppression of exploratory behavior in response to CS+ or CS - presentations $(p>0.05)$, the group receiving a higher dose of AM404 (50 $\mathrm{ng} / 0.5 \mu \mathrm{l}$ ) demonstrated significant suppression of exploratory behavior specifically in response to CS + versus CS - presentations $(p<0.01)$. Furthermore, comparing exploratory behavior suppression during CS + presentations across groups revealed significantly greater CS+ exploratory suppression in the group 
receiving the higher dose of AM404 (50 ng/0.5 $\mu \mathrm{l})$ (Fig. 2D) than the vehicle control or the group receiving the lower dose $(p<$ 0.01 ). Thus, inhibition of anandamide reuptake directly within the BLA produces behavioral effects similar to those observed previously with direct intra-BLA CB1 receptor activation (Fig. $2 A, B$ ), as demonstrated by potentiated associative memory for CS+ presentations paired previously with a normally subthreshold fear-conditioning footshock stimulus.

\section{BLA cannabinoid receptor-mediated potentiation of fear memory acquisition requires the PLC}

Given that functional interactions between the BLA and PLC have been reported to be critical for cannabinoid modulation of emotional memory formation (Laviolette and Grace, 2006a; Tan et al., 2010), we next examined the potential role of the mPFC in the observed potentiation of olfactory fear memory acquisition after direct intra-BLA CB1 receptor activation. Accordingly, four experimental groups received quadruple cannulations aimed at the BLA and PLC, and the effects of intra-BLA CB1 receptor activation on emotional learning potentiation with the highest behaviorally effective dose of WIN 55,212-2 (500 ng/0.5 $\mu \mathrm{l}$ ) were challenged with pharmacological inactivation of the PLC with microinfusions of the $\mathrm{GABA}_{\mathrm{A}}$ receptor agonist muscimol (500 $\mathrm{ng} / 0.5 \mu \mathrm{l}$ ) (see Materials and Methods) or vehicle, immediately before receiving intra-BLA WIN 55,212-2 (500 ng/0.5 $\mu \mathrm{l})$ before olfactory fear conditioning with the subthreshold footshock stimulus $(0.4 \mathrm{~mA})$. Comparing times spent freezing in response to CS+ versus CS- presentations, for experimental groups receiving either intra-PLC vehicle $(n=7)$ or muscimol (500 ng/0.5 $\mu \mathrm{l} ; n=7)$ before receiving the previously determined highest effective dose of intra-BLA WIN 55,212-2 (500 ng/0.5 $\mu \mathrm{l})$, twoway ANOVA revealed a significant interaction between group and treatment $\left(F_{(1,27)}=117.5 ; p<0.001\right)$ (Fig. 3A). Post hoc analyses revealed that whereas intra-PLC vehicle controls showed significantly greater amounts of freezing behavior specifically in response to CS+ presentations relative to CS - presentations $(p<0.01)$, for rats receiving intra-PLC muscimol (500 ng/0.5 $\mu \mathrm{l})$ before intra-BLA WIN 55,212-2 (500 ng/0.5 $\mu \mathrm{l})$, no significant difference was observed in freezing responses during presentations of the CS + or CS - odor cues $(p>0.05)$. Furthermore, CS+-specific freezing levels were significantly lower in rats receiving intra-PLC muscimol than in vehicle controls $(p<0.01)$. Thus, pharmacological inactivation of the PLC blocks the ability of intra-BLA CB1 receptor activation to potentiate emotional memory encoding to a subthreshold footshock stimulus (0.4 $\mathrm{mA})$.

Comparing exploratory scores in response to CS+ versus CS- presentations, for experimental groups receiving either intra-PLC vehicle $(n=7)$ or muscimol (500 ng/ $0.5 \mu \mathrm{l} ; n=7$ ) before receiving the previously determined effective dose of intra-BLA WIN 55,212-2 (500 ng/0.5 $\mu \mathrm{l})$, two-way ANOVA revealed a significant interaction between group and treatment $\left(F_{(1,27)}=20.5 ; p<0.01\right)$ (Fig. 3B). Post hoc analyses revealed that whereas intra-PLC vehicle controls showed significantly greater amounts of exploratory behavior suppression specifically in response to CS+ presentations relative to CS - presentations $(p<$ 0.01 ), for rats receiving intra-PLC muscimol ( $500 \mathrm{ng} / 0.5 \mu \mathrm{l})$ before intra-BLA WIN 55,212-2 (500 ng/0.5 $\mu \mathrm{l})$, no significant difference was observed in freezing responses during presentations of the CS + or CS - odor cues $(p>0.05)$. Thus, pharmacological inactivation of the PLC blocks the ability of intra-BLA CB1 receptor activation to potentiate conditioned exploratory behavior suppression in response to CS+ presentations after conditioning

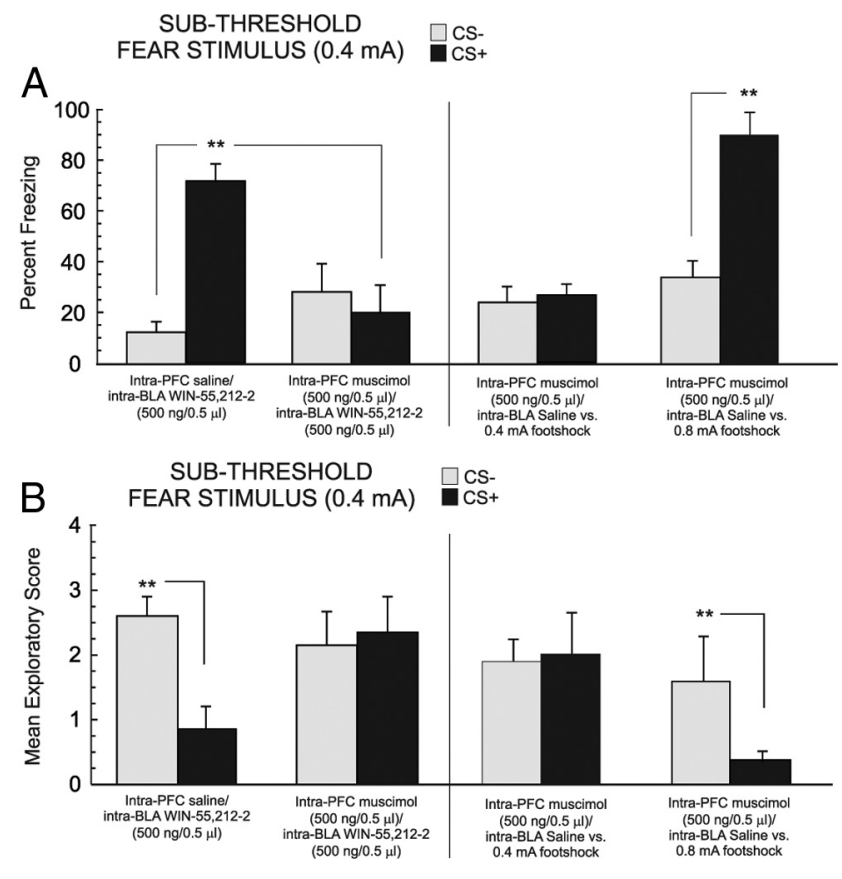

Figure 3. Effects of pharmacological inactivation of the mPFC on intra-BLA CB1 receptor-mediated potentiation of emotional memory encoding. $A, B$, Relative to a control group receiving intra-mPFC vehicle $(n=7)$, rats receiving intra-mPFC muscimol ( 500 $\mathrm{ng} / 0.5 \mu \mathrm{l} ; n=7)$ before intra-BLA WIN $55,212-2(500 \mathrm{ng} / 0.5 \mu \mathrm{l})$ failed to show potentiation of emotional memory encoding during conditioning to a subthreshold footshock stimulus $(0.4 \mathrm{~mA})(\boldsymbol{A})$ or potentiation of conditioned suppression of exploratory behavior during $(S+$ presentations $(\boldsymbol{B})$. This same dose of intra-mPFC muscimol $(500 \mathrm{ng} / 0.5 \mu \mathrm{l})$ fails to block fear memory acquisition or conditioned suppression of exploratory behavior to either suprathreshold $(0.8 \mathrm{~mA})$ or subthreshold $(0.4 \mathrm{~mA})$ footshock-conditioning levels (right side of $\boldsymbol{A}$ and $\boldsymbol{B}$, respectively; each $n=7$ ).

to a subthreshold footshock stimulus $(0.4 \mathrm{~mA})$. To control for the possibility that this dose of intra-PLC muscimol ( $500 \mathrm{ng} / 0.5 \mu \mathrm{l})$ may in and of itself produce learning or memory impairments, we next ran additional control experiments wherein rats received intra-PLC muscimol $(500 \mathrm{ng} / 0.5 \mu \mathrm{l})$ before intra-BLA vehicle using either the suprathreshold footshock-conditioning stimulus ( $n=7 ; 0.8 \mathrm{~mA}$ ) or subthreshold footshock-conditioning stimulus ( $n=7 ; 0.4 \mathrm{~mA}$ ) (see Materials and Methods). Analysis of freezing behavior in rats receiving intra-PLC muscimol (500 ng/ $0.5 \mu \mathrm{l}$ ) administration before olfactory fear conditioning with the subthreshold footshock level $(0.4 \mathrm{~mA})$ revealed no effect on associative fear memory acquisition as rats displayed no difference in freezing behavior between CS + and CS- presentations when tested $24 \mathrm{~h}$ after conditioning $\left(t_{(6)}=0.35 ; p>0.05\right.$ ) (Fig. $3 A$, right). Similarly, analysis of conditioned suppression of exploratory behavior revealed no effect of intra-PLC muscimol administration as rats displayed no differences in exploratory behavior suppression in response to CS+ relative to CS - presentations $\left(t_{(6)}=0.68 ; p>0.05\right)$ (Fig. 3B, right). Analysis of freezing behavior in rats receiving intra-PLC muscimol $(500 \mathrm{ng} / 0.5 \mu \mathrm{l})$ administration before olfactory fear conditioning with a suprathreshold footshock level $(0.8 \mathrm{~mA})$ revealed no effect on associative fear memory as rats displayed significantly greater levels of freezing to $\mathrm{CS}+$ than to CS - presentations when tested $24 \mathrm{~h}$ after conditioning $\left(t_{(6)}=7.42 ; p<0.01\right)$ (Fig. $3 A$, far right). Similarly, analysis of conditioned suppression of exploratory behavior revealed no effect of intra-PLC muscimol administration as rats displayed significantly greater levels of exploratory behavior suppression specifically in response to CS + than to CS - presenta- 
tions $\left(t_{(6)}=3.49 ; p<0.01\right)$ (Fig. $3 B$, far right). Thus, although this dose of intra-PLC muscimol $(500 \mathrm{ng} / 0.5 \mu \mathrm{l})$ is sufficient to block the effects of intra-BLA CB1 receptor activation on potentiation of emotional memory encoding, it does not in and of itself produce nonspecific learning or memory impairments during conditioning to either suprathreshold or subthreshold levels of footshock stimuli.

\section{Blockade or activation of $\mathrm{CB} 1$ receptor transmission in the BLA does not influence footshock sensitivity}

To examine whether the observed behavioral effects produced by either blockade or activation of intra-BLA CB1 receptors might be explained by possible sensory or nociceptive alterations during exposure to either the subthreshold $(0.4 \mathrm{~mA})$ or suprathreshold $(0.8 \mathrm{~mA})$ footshock stimulus levels, we performed separate experiments using a battery of behavioral sensitivity measures after footshock administration (see Materials and Methods), to examine how intra-BLA administration of the highest tk;4behaviorally effective doses of either AM251 (500 ng/0.5 $\mu \mathrm{l}$ ) or WIN 55,212-2 (500 ng/0.5 $\mu \mathrm{l}$ ) may influence sensitivity to either subthreshold or suprathreshold footshock administration. When we compared rats receiving the highest effective dose of intra-BLA WIN $55,212-2$ ( $500 \mathrm{ng} / 0.5 \mu \mathrm{l} ; n=7)$ or vehicle $(n=7)$ during exposure to subthreshold footshock $(0.4 \mathrm{~mA})$, no significant differences were observed between vehicle control and intra-BLA WIN 55,212-2-treated rats in amount of freezing behavior immediately after footshock administration [intra-BLA vehicle, mean = $11.2 \pm 5.1$ (SEM) vs intra-BLA WIN 55,212-2, mean $=11.8 \pm 5.3$ $\left.(\mathrm{SEM}) ; t_{(6)}=0.23 ; p>0.05\right]$, or in mean exploratory scores after footshock presentations [intra-BLA vehicle, mean $=1.2 \pm 0.28$ $(\mathrm{SEM})$ vs intra-BLA WIN 55,212-2, mean $=1.79 \pm 0.2(\mathrm{SEM})$; $\left.t_{(6)}=1.79 ; p>0.05\right]$. Furthermore, we observed no significant differences across trials in the number of rearing events displayed by either the WIN 55,212-2 or vehicle control groups [intra-BLA vehicle, mean $=4.84 \pm 2.2($ SEM) vs intra-BLA WIN 55,212-2, mean $\left.=4.8 \pm 1.7(\mathrm{SEM}) ; t_{(6)}=0.01 ; p>0.05\right]$ or in levels of footshock-induced defecation (measured in grams) between the WIN 55,212-2 and the vehicle control groups [intra-BLA vehicle, mean $=1.2 \pm 0.88($ SEM $)$ vs intra-BLA WIN 55,212-2, mean $=$ $\left.0.74 \pm 0.39(\mathrm{SEM}) ; t_{(6)}=1.24 ; p>0.05\right]$.

When groups receiving the highest effective dose of intra-BLA AM251 (500 ng/0.5 $\mu \mathrm{l} ; n=6)$ or vehicle $(n=6)$ during suprathreshold footshock $(0.8 \mathrm{~mA})$ exposure were compared, no significant differences were observed between vehicle control and intra-BLA AM251-treated rats in the percentage amount of freezing behavior immediately after footshock administration [intraBLA vehicle, mean $=60.1 \pm 5.2(\mathrm{SEM})$ vs intra-BLA AM251, mean $\left.=70.8 \pm 4.9(\mathrm{SEM}) ; t_{(5)}=1.97 ; p>0.05\right]$ or in levels of footshock-evoked jumps between the AM251 and vehicle groups [intra-BLA vehicle, mean $=4.3 \pm 0.21(\mathrm{SEM})$ vs intra-BLA $\mathrm{AM} 251$, mean $\left.=4.5 \pm 0.3(\mathrm{SEM}) ; t_{(5)}=1.2 ; p>0.05\right]$. Furthermore, we observed no significant differences across trials in the number of rearing events displayed by either the AM251 or vehicle control groups [intra-BLA vehicle, mean $=10.02 \pm 5.3$ $(\mathrm{SEM})$ vs intra-BLA AM251, mean $=12.8 \pm 4.8(\mathrm{SEM}) ; t_{(5)}=$ $0.51 ; p>0.05$ ] or in footshock-induced defecation (measured in grams) between the AM251 and vehicle control groups [intraBLA vehicle, mean $=2.03 \pm 0.43(\mathrm{SEM})$ vs intra-BLA AM251, mean $\left.=1.94 \pm 0.46(\mathrm{SEM}) ; t_{(5)}=0.18 ; p>0.05\right]$. These results demonstrate that pharmacological blockade or activation of intra-BLA CB1 receptors with the highest behaviorally effective doses of either AM251 or WIN 55,212-2 did not produce any observable effects (either increases or decreases) in behavioral indices of footshock sensitivity. Note that for groups receiving subthreshold (0.4 mA) footshock presentations, "jumping" behavior was not observed in either control or WIN 55,212-2 groups after subthreshold footshock $(0.4 \mathrm{~mA})$ presentations (zero levels for both groups). In addition, for groups receiving the suprathreshold $(0.8 \mathrm{~mA})$ footshock presentations, "exploratory scores" were consistently zero in both control and AM251 groups after suprathreshold footshock presentations; hence, data for these two measures are not presented.

\section{CB1 receptor activation in the BLA increases spontaneous neuronal activity in the PLC}

Given that pharmacological inactivation of the PLC was sufficient to prevent the behavioral effects of intra-BLA CB1 receptor activation on emotional memory encoding potentiation (Fig. 3), we next examined the effects of direct activation of $\mathrm{CB} 1$ receptors within the BLA on single-neuron activity patterns recorded simultaneously in the PLC, using our previously determined highest behaviorally effective doses for potentiating subthreshold emotional fear-conditioning acquisition (Fig. 2). We sampled a total of $n=101$ PLC neurons during intra-BLA microinfusion studies using AM251 or WIN 55,212-2. Average baseline spontaneous neuronal frequency across all sampled neurons was $5.4 \pm$ $0.62 \mathrm{~Hz}$ (SEM). A total of $n=51$ neurons within the PLC were sampled during intra-BLA administration of the two highest behaviorally effective doses of WIN 55,212-2: $50 \mathrm{ng} / 0.5 \mu \mathrm{l}(n=26)$ and $500 \mathrm{ng} / 0.5 \mu \mathrm{l}(n=25)$. Results from all sampled neurons across both doses of WIN 55,212-2 are summarized in Figure 4A. Relative to preinfusion baseline activity levels, for rats receiving the lower dose of intra-BLA WIN 55,212-2 (50 ng/0.5 $\mu \mathrm{l}$ ), 54\% of neurons showed increased activity, $15 \%$ showed decreased activity, and 31\% demonstrated no change in activity levels. Similarly, relative to preinfusion baseline activity levels, for rats receiving the higher dose of intra-BLA WIN 55,212-2 (500 ng/0.5 $\mu \mathrm{l}$ ), 60\% of neurons showed increased activity, $28 \%$ showed decreased activity, and $12 \%$ demonstrated no change in activity levels. Thus, for both behaviorally effective doses of intra-BLA WIN 55,212-2, a plurality of the sample tested demonstrated a post-BLA infusion increase in spontaneous neuronal activity patterns recorded in the $\mathrm{mPFC}$, relative to preinfusion baseline levels. In Figure 4, $B$ and $C$, we present group data for in vivo neuronal recordings performed in the PLC during intra-BLA WIN 55,212-2 administration $(n=12$, vehicle control; $n=14,50 \mathrm{ng} / 0.5 \mu \mathrm{l} ; n=15,500$ $\mathrm{ng} / 0.5 \mu \mathrm{l})$ for the subpopulations of PLC neurons that specifically demonstrated increased firing frequency after intra-BLA WIN 55,212-2 administration. Comparing average neuronal firing frequency between before and after intra-BLA drug infusion across groups, two-way ANOVA revealed a significant interaction between treatment and group $\left(F_{(2,74)}=4.88 ; p<0.05\right)$. Post hoc analyses revealed that PLC neuronal firing frequency was significantly increased relative to baseline levels at both the lower (50 ng/0.5 $\mu \mathrm{l}$ ) and higher $(500 \mathrm{ng} / 0.5 \mu \mathrm{l}$ ) doses of intra-BLA WIN $55,212-2(p<0.01)$ (Fig. $4 B, C)$ but not in vehicle control recordings $(p>0.05)$. Thus, across both doses of intra-BLA WIN $55,212-2$ that were behaviorally effective in potentiating the associative encoding of normally subthreshold fear-conditioning footshock stimuli (Figs. 2, 3), CB1 receptor activation increased spontaneous neuronal activity in a plurality (57\%) of sampled neurons within the PLC (Fig. $4 A, C$ ). Interestingly, smaller subpopulations of neurons also demonstrated decreased spontaneous activity after intra-BLA infusions of the two behaviorally effective doses of WIN 55,212-2 (50 ng/0.5 $\mu \mathrm{l}, n=4 ; 500 \mathrm{ng} / 0.5$ $\mu l, n=7)$. Comparing average neuronal firing frequency be- 

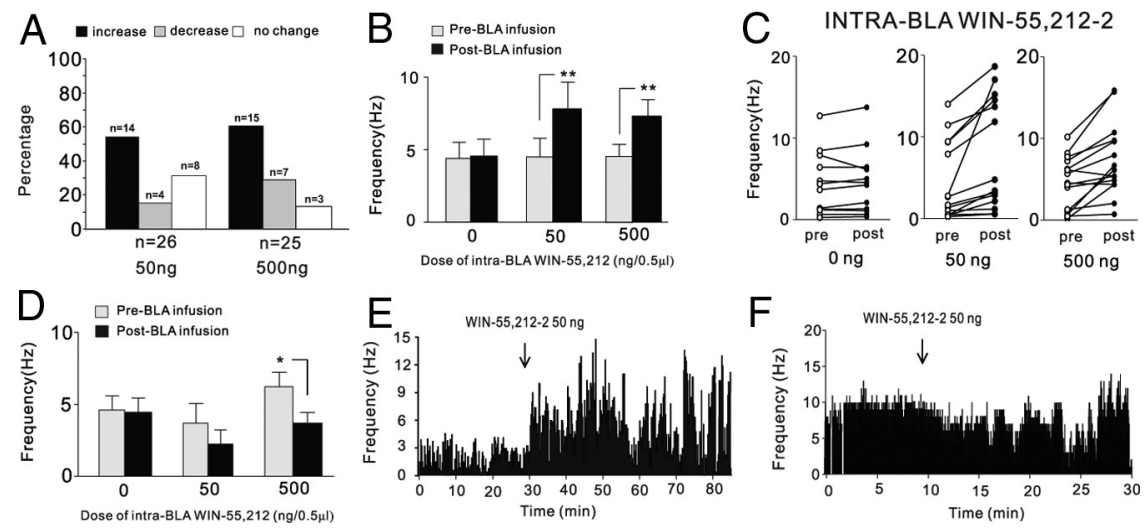

Figure 4. Effects of intra-BLA WIN 55,212-2 on spontaneous neuronal activity in the mPFC. A, Summary of the postinfusion effects of intra-BLA WIN 55,212-2 (50-500 $\mathrm{ng} / 0.5 \mu \mathrm{l})$ on spontaneous firing frequency of sampled neurons recorded in the PLC subdivision of the mPFC. B, Intra-BLA microinfusions of the behaviorally effective doses of WIN 55,212-2 (50 and $500 \mathrm{ng} / 0.5 \mu$ l) cause significant increases in spontaneous firing activity levels after infusion. $\boldsymbol{C}$, Individual data points from all sampled neurons

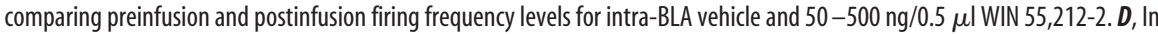
contrast, intra-BLA WIN 55,212-2 produces inhibitory responses in a smaller subpopulation of sampled PLC neurons, which is significant at only the highest behaviorally effective dose of WIN 55,212-2 (500 ng/0.5 $\mu$ l). $E, F$, Representative PLC neuronal recording samples demonstrating a typical increase in neuronal activity after intra-BLA WIN 55,212-2 (500 ng/0.5 $\mu$ l) (E), and a representative case showing decreased neuronal activity after intra-BLA WIN 55,212-2 (50 ng/0.5 $\mu \mathrm{l})(\boldsymbol{F})$.
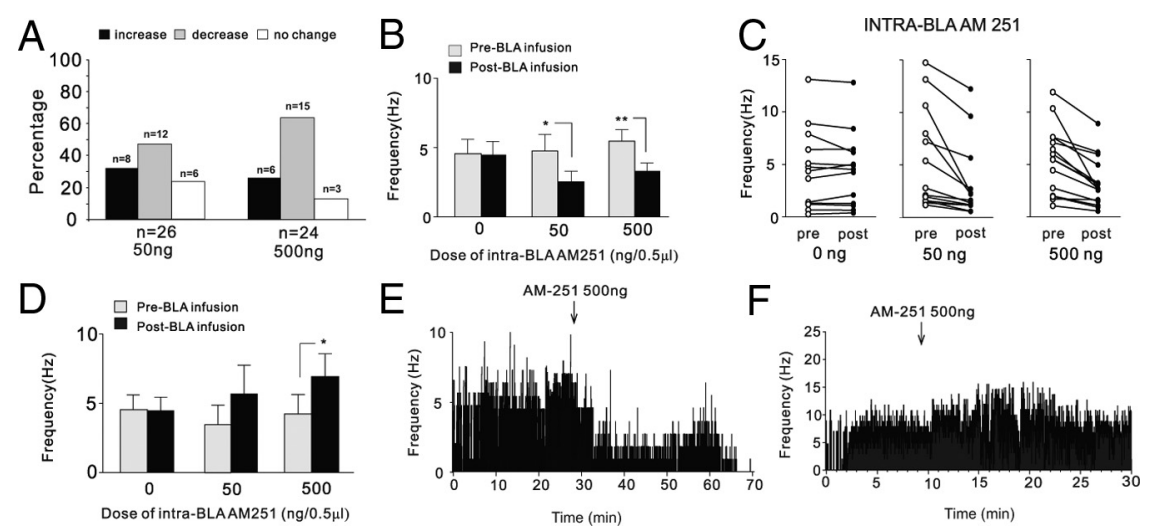

Figure 5. Effects of intra-BLA AM251 on spontaneous neuronal activity in the $\mathrm{MPFC}$. $A$, Summary of the postinfusion effects of intra-BLA AM251 ( $50-500 \mathrm{ng} / 0.5 \mu \mathrm{l}$ ) on spontaneous firing frequency of sampled neurons recorded in the PLC subdivision of the mPFC. $B$, Intra-BLA microinfusions of the behaviorally effective doses of AM251 ( 50 and $500 \mathrm{ng} / 0.5 \mu \mathrm{l}$ ) cause significant decreases in spontaneous firing activity levels after infusion. $\boldsymbol{C}$, Individual data points from all sampled neurons comparing preinfusion and postinfusion firing frequency levels for intra-BLA vehicle versus $50-500 \mathrm{ng} / 0.5 \mu$ IM251. D, In contrast, intra-BLA AM251 produces excitatory responses in a smaller subpopulation of sampled PLC neurons, which is significant at only the highest behaviorally effective dose of AM251 (500 ng/0.5 $\mu \mathrm{l})$. $E, F$, Representative PLC neuronal recording samples demonstrating a typical decrease in neuronal activity after intra-BLA AM251 $(500 \mathrm{ng} / 0.5 \mu \mathrm{l})(\boldsymbol{E})$, and a representative case showing increased neuronal activity after intra-BLA AM251 $(500 \mathrm{ng} / 0.5 \mu \mathrm{l})(\boldsymbol{F})$.

tween before and after intra-BLA drug infusion across groups (Fig. 4D), two-way ANOVA revealed a significant main effect of treatment on firing rates before versus after infusion $\left(F_{(1,21)}=\right.$ $4.21 ; p<0.05)$. Post hoc analyses revealed that PLC neuronal firing frequency was significantly decreased relative to baseline levels at the higher $(500 \mathrm{ng} / 0.5 \mu \mathrm{l})$ dose of intra-BLA WIN $55,212-2$ but not at the lower $(50 \mathrm{ng} / 0.5 \mu \mathrm{l})$ or in the vehicle control group $(p>0.05)$ (Fig. $4 D)$. Thus, whereas intra-BLA WIN 55,212-2 induced significant increases in spontaneous activity in a plurality of sampled PLC neurons and over an order of magnitude dose range ( $50-500 \mathrm{ng} / 0.5 \mu \mathrm{l})$, inhibitory effects were observed only in a smaller subpopulation of sampled neurons and were only significant at the highest tested dose of WIN 55,212-2 (500 ng/0.5 $\mu \mathrm{l})$. In Figure 5, $E$ and $F$, we present two representative firing rate rastergrams from two recorded PLC neurons showing the more typical firing rate increase pattern (Fig. $4 E$ ) and an example of the less typical inhibitory response after intra-BLA WIN 55,212-2 (Fig. $4 F)$ (50 ng).

\section{Blockade of $\mathrm{CB} 1$ receptor transmission in the BLA inhibits neuronal activity in the mPFC}

We next examined the effects of direct blockade of $\mathrm{CB} 1$ receptors within the BLA on single-neuron activity patterns recorded simultaneously in the mPFC, using our previously determined highest behaviorally effective doses for blocking the acquisition of suprathreshold olfactory fear memory (Fig. 1). A total of $n=$ 50 neurons within the PLC were sampled during intra-BLA administration of AM251 at $50 \mathrm{ng} / 0.5 \mu \mathrm{l}(n=26)$ or $500 \mathrm{ng} / 0.5 \mu \mathrm{l}$ $(n=24)$. Results from all recorded neurons across both doses of intra-BLA AM251 are summarized in Figure 5A. Relative to preinfusion baseline activity levels, for rats receiving the lower dose of intra-BLA AM251 (50 ng/0.5 $\mu$ l), 46\% of neurons showed decreased activity, $31 \%$ showed increased activity, and 23\% demonstrated no change in spontaneous activity levels. For rats receiving the higher dose of intra-BLA AM251 (500 ng/0.5 $\mu \mathrm{l}$ ), $62 \%$ of neurons showed decreased activity, 25\% showed increased activity, and $13 \%$ demonstrated no change in activity levels. Thus, for both behaviorally effective doses of intra-BLA AM251, a plurality of neurons within each group demonstrated a decrease in spontaneous neuronal activity patterns recorded in the mPFC, relative to preinfusion baseline levels. In Figure 5, $B$ and $C$, we present group data for in vivo neuronal recordings performed in the PLC during intra-BLA AM251 administration $(n=12,50 \mathrm{ng} / 0.5$ $\mu \mathrm{l} ; n=15,500 \mathrm{ng} / 0.5 \mu \mathrm{l}$ ) for the subpopulations of PLC neurons that specifically demonstrated decreased firing frequency after intra-BLA AM251 administration. Comparing average neuronal firing frequency between before and after intra-BLA drug infusion, two-way ANOVA revealed a significant interaction between treatment and group $\left(F_{(2,73)}=4.97 ; p<0.0001\right)$. Post hoc analyses revealed that mPFC neuronal firing frequency was significantly decreased relative to baseline levels at both the lower $(50 \mathrm{ng} / 0.5 \mu \mathrm{l})$ and higher $(500$ $\mathrm{ng} / 0.5 \mu \mathrm{l})$ doses of intra-BLA AM251 $(p<0.01)$ (Fig. $5 B, C$ ). Thus, after administration of doses of intra-BLA AM251 that completely blocked the associative encoding of suprathreshold fear-conditioning footshock stimuli behaviorally (Fig. 1), CB1 receptor blockade within the BLA inhibits spontaneous neuronal activity in a plurality (54\%) of all sampled PLC neurons. However, similar to the mixed effects on spontaneous activity observed after intra-BLA WIN 55,212-2 infusions (Fig. 4), a smaller subpopulation of neurons also demonstrated increased sponta- 
neous activity after intra-BLA infusions of the two behaviorally effective doses of AM251 ( $50 \mathrm{ng} / 0.5 \mu \mathrm{l}, n=8 ; 500 \mathrm{ng} / 0.5 \mu \mathrm{l}, n=$ 6). Comparing average neuronal firing frequency between before and after intra-BLA drug infusion across these groups (Fig. 5D), two-way ANOVA revealed a significant main effect of treatment on preinfusion versus postinfusion firing rates $\left(F_{(1,24)}=4.29 ; p<\right.$ 0.05). Post hoc analyses revealed that PLC neuronal firing frequency was significantly increased relative to baseline levels at the higher dose $(500 \mathrm{ng} / 0.5 \mu \mathrm{l})$ of intra-BLA AM251, but not at the lower dose $(50 \mathrm{ng} / 0.5 \mu \mathrm{l})$ or in the vehicle control group $(p>$ 0.05 ) (Fig. 5D). Thus, whereas intra-BLA AM251 induced significant inhibition of spontaneous activity in a plurality of sampled PLC neurons and over an order of magnitude dose range (50-500 $\mathrm{ng} / 0.5 \mu \mathrm{l}$ ), excitatory effects were observed only in a smaller subpopulation of sampled neurons and were only significant at the highest tested dose of AM251 (500 ng/0.5 $\mu \mathrm{l})$. In Figure 5, E and $F$, we present two representative firing rate rastergrams from two recorded PLC neurons showing the more typical firing rate decrease pattern (Fig. $5 E$ ) and an example of a less typical excitatory response after intra-BLA AM251 (Fig. 5F) (500 ng).

\section{Activation or blockade of $\mathrm{CB} 1$ receptor transmission in the BLA modulates neuronal bursting activity in the PLC}

Given that $\mathrm{mPFC}$ neuronal bursting activity has been associated with the acquisition and expression of associative fear memory (Laviolette et al., 2005; Laviolette and Grace, 2006a), we next examined the potential effects of intra-BLA CB1 receptor modulation on spontaneous neuronal bursting activity within the PLC, focusing on the subpopulations of PLC neurons previously demonstrating increases in spontaneous activity after intra-BLA CB1 receptor activation (Fig. $4 A, C$ ) or decreases in spontaneous activity after intra-BLA CB1 receptor blockade (Fig. $5 A, C$ ). Analysis of bursting activity in PLC neurons (see Materials and Methods) after intra-BLA administration of AM251 (50-500 ng/ $0.5 \mu \mathrm{l})$ revealed significant suppression of spontaneous bursting activity relative to preinfusion baseline levels (Fig. 6A,B). Comparing the number of burst events per minute between vehicle control $(n=13)$ and $50 \mathrm{ng} / 0.5 \mu \mathrm{l}(n=12)$ and $500 \mathrm{ng} / 0.5 \mu \mathrm{l}(n=$ $15)$, one-way ANOVA revealed a significant effect of treatment $\left(F_{(2,43)}=4.6 ; p<0.05\right)$ on the average number of bursts occurring between pre- and post-BLA infusion PLC neuronal recording epochs. Post hoc analyses revealed that whereas neurons recorded in vehicle controls showed no significant difference between preinfusion and postinfusion recordings, groups receiving either 50 or $500 \mathrm{ng}$ doses of intra-BLA AM251 demonstrated significantly fewer burst events per minute $(p<0.05)$ (Fig. 6A). Comparing the number of spikes per burst event between vehicle control $(n=13)$ and $50 \mathrm{ng} / 0.5 \mu \mathrm{l}(n=12)$ and $500 \mathrm{ng} / 0.5 \mu \mathrm{l}(n=$ $15)$, one-way ANOVA revealed a significant effect of treatment $\left(F_{(2,43)}=4.45 ; p<0.05\right)$ on the average number of spikes per burst occurring between pre- and post-BLA infusion PLC neuronal recording epochs. Post hoc analyses revealed that whereas neurons recorded in vehicle controls showed no significant difference between preinfusion and postinfusion recordings, groups receiving either 50 or $500 \mathrm{ng}$ doses of intra-BLA AM251 demonstrated significantly fewer burst events per minute $(p<0.05)$ (Fig. 6B).

For groups receiving intra-BLA WIN 55,212-2, comparing the number of burst events per minute between preinfusion baseline recording and postinfusion recording across vehicle control $(n=$ $13)$ and $50 \mathrm{ng} / 0.5 \mu \mathrm{l}(n=14)$ and $500 \mathrm{ng} / 0.5 \mu \mathrm{l}(n=15)$, one-way ANOVA revealed a significant effect of treatment $\left(F_{(2,40)}=3.84 ; p<0.05\right)$ on the average number of bursts occur-
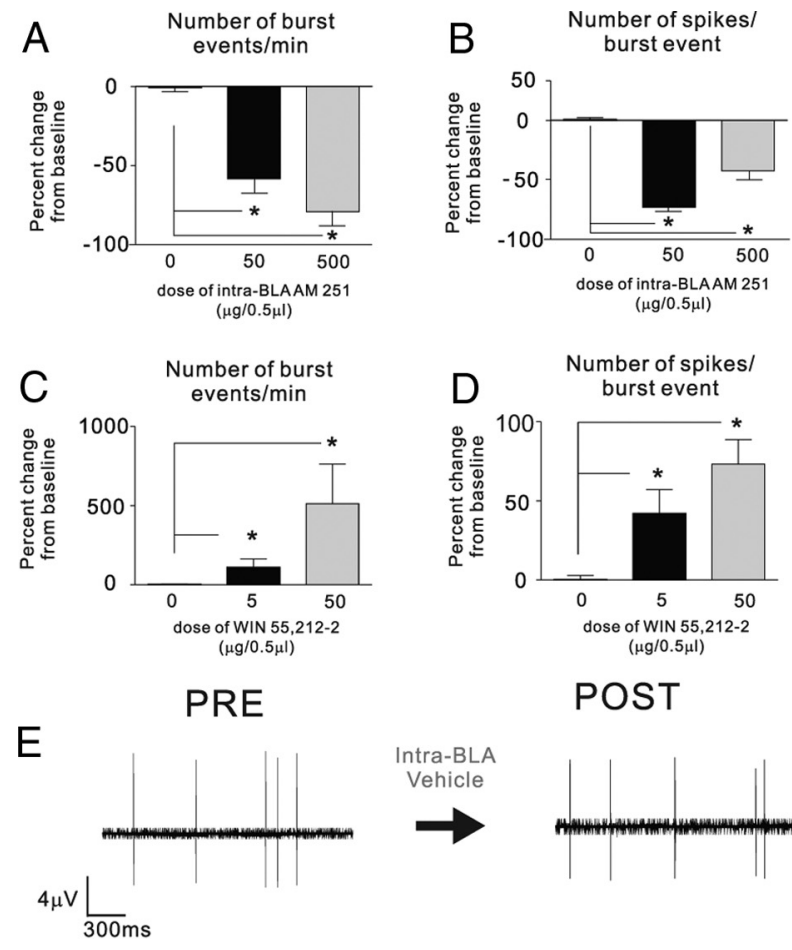

POST
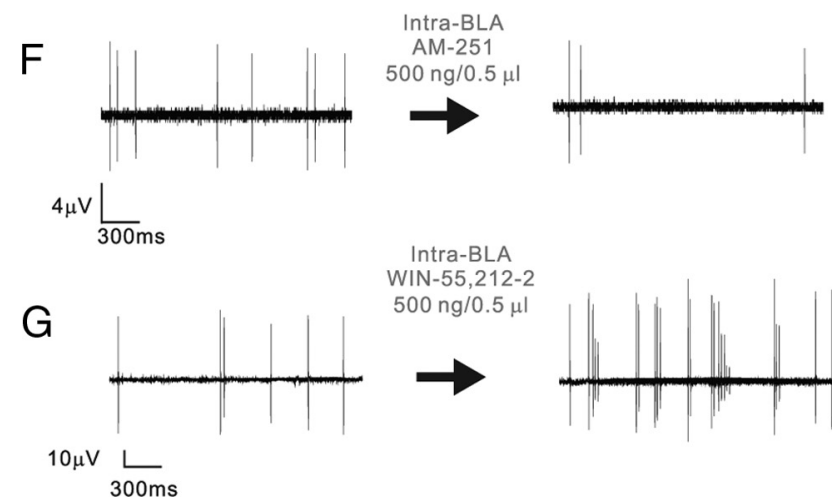

Intra-BLA WIN-55,212-2 $500 \mathrm{ng} / 0.5 \mu \mathrm{l}$
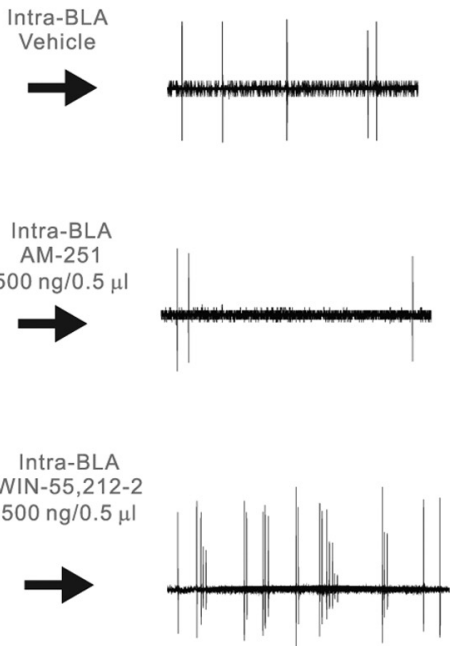

Figure 6. Effects of intra-BLA AM251 and WIN 55,212-2 on spontaneous neuronal bursting activity in the mPFC. $A, B$, Relative to preinfusion baseline levels, intra-BLA administration of behaviorally effective doses of AM251 (50 - 500 ng/0.5 $\mu$ l) significantly depresses spontaneous numbers of bursting events in PLC neurons $(\boldsymbol{A})$ as well as average number of spikes per burst event $(\boldsymbol{B}) . \boldsymbol{C}, \boldsymbol{D}$, Relative to preinfusion baseline levels, intra-BLA administration of behaviorally effective doses of WIN $55,212-2(50-500 \mathrm{ng} / 0.5 \mu \mathrm{l})$ significantly increases spontaneous numbers of bursting events in PLC neurons $(C)$ as well as average number of spikes per burst event (D). $\boldsymbol{E}-\boldsymbol{G}$, Representative PLC neuronal recording samples demonstrating typical spike activity patterns before and after intra-BLA vehicle $(\boldsymbol{E})$, AM251 (500 ng/0.5 $\mu \mathrm{l} ; \boldsymbol{F})$, and WIN 55,212-2 (500 ng/0.5 $\mu \mathrm{l} ; \boldsymbol{G})$.

ring between pre- and post-BLA infusion PLC neuronal recording epochs. Post hoc analyses revealed that whereas neurons recorded in vehicle controls showed no significant difference between preinfusion and postinfusion recordings, groups receiving either 50 or 500 ng doses of intra-BLA WIN 55,212-2 demonstrated significantly higher levels of burst events per minute $(p<$ 0.05 ) (Fig. 6C). Similarly, comparing the number of spikes per burst event between vehicle control and $50 \mathrm{ng} / 0.5 \mu \mathrm{l}$ or $500 \mathrm{ng} /$ $0.5 \mu \mathrm{l}$, one-way ANOVA revealed a significant effect of treatment $\left(F_{(2,40)}=7.85 ; p<0.001\right)$ on the average number of spikes per burst occurring between pre- and post-BLA infusion PLC neuronal recording epochs. Post hoc analyses revealed that whereas neurons recorded in vehicle controls showed no significant difference between preinfusion and postinfusion recordings, groups 


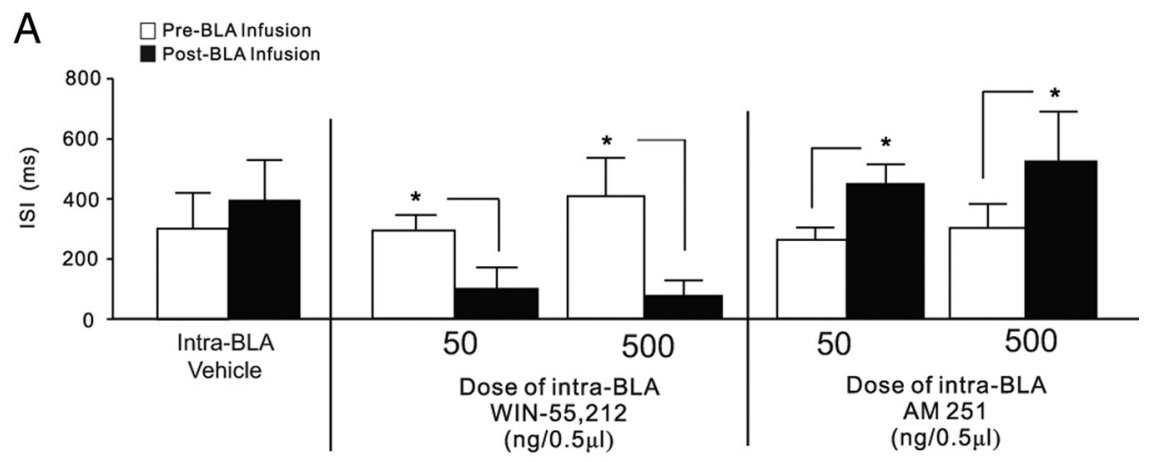

INTRA-BLA VEHICLE CONTROL
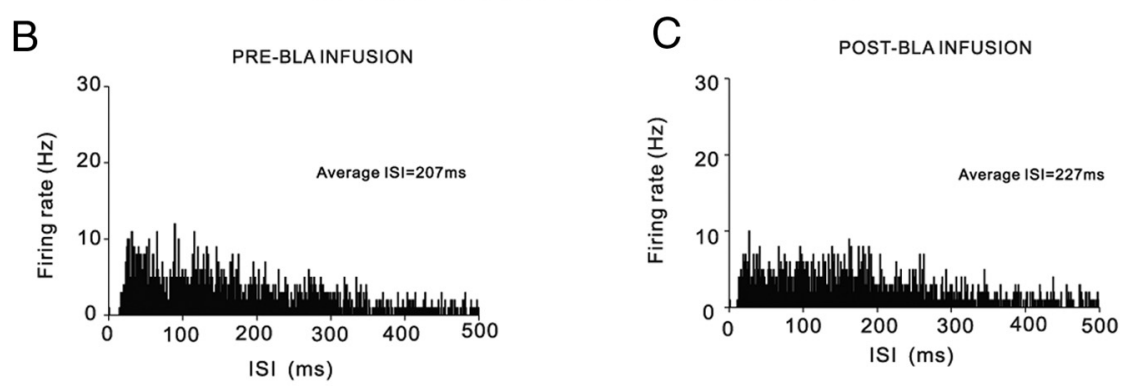

INTRA-BLA WIN-55 212-2 (500 ng/0.5 $\mu$ I)

D

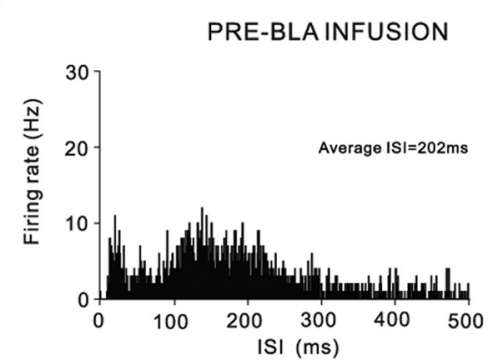

$\mathrm{E}$

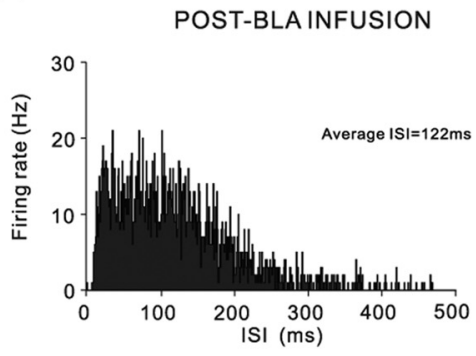

INTRA-BLA AM $251(500 \mathrm{ng} / 0.5 \mu \mathrm{l})$

F

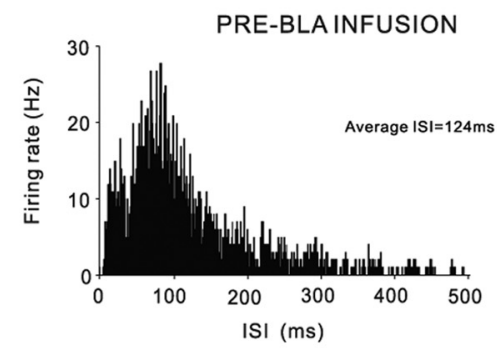

G

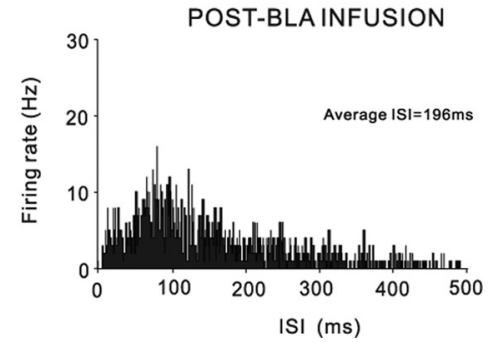

Figure 7. Effects of intra-BLA vehicle, WIN 55,212-2 or AM251 on ISI distributions in PLC neuronal populations. $\boldsymbol{A}$, Intra-BLA infusions of vehicle produced no significant change in average ISI levels before versus after infusion, whereas infusions of the highest behaviorally effective dose of intra-BLA WIN 55,212-2 (50-500 ng/0.5 $\mu \mathrm{l})$ induced significant decreases in average ISI levels after infusion. In contrast, infusions of the highest behaviorally effective doses of intra-BLA AM251 (50-500 ng/0.5 $\mu$ l) induced significant increases in average ISI levels after infusion. B, C, Sample rastergram showing representative ISI distribution before $B L A$ vehicle infusion $(\boldsymbol{B})$, and the same neuron after infusion of vehicle (C). $\boldsymbol{D}, \boldsymbol{E}$, Sample rastergram showing representative pre-BLA WIN 55,212-2 (500 ng/0.5 $\mu$ l) infusion ISI distribution (D), and the same neuron after infusion $(\boldsymbol{E})$. $\boldsymbol{F}, \boldsymbol{G}$, Sample rastergram showing representative pre-BLA AM251 (500 ng/0.5 $\mu$ l) infusion ISI distribution (F), and the same neuron after infusion (G).
$6 E)$, intra-BLA AM251 (500 ng/0.5 $\mu \mathrm{l})$

(Fig. $6 F$ ), and intra-BLA WIN 55,212-2 (500 ng/0.5 $\mu \mathrm{l}$ ) (Fig. 6G). Thus, activation or inhibition of intra-BLA CB1 receptor transmission modulates both bursting event frequency and the number of spikes within each burst event, within subpopulations of PLC neurons.

We have reported previously that associative bursting activity within $\mathrm{mPFC}$ neurons in vivo is associated with leftward ISI shifts in response to CS+ presentations demonstrated by shorter ISI intervals with increasing bursting activity (Laviolette et al., 2005; Laviolette and Grace, 2006a). Accordingly, we analyzed ISI distributions across the same neuronal groups described above [intra-BLA microinfusions of our previously established behaviorally effective doses of either AM251 (50-500 ng/0.5 $\mu \mathrm{l})$ or WIN 55,212-2 (50-500 ng/0.5 $\mu \mathrm{l})]$. Comparing pre- versus post-intra-BLA infusion epochs during PLC neuronal recordings revealed that intra-BLA vehicle infusions had no significant effect on ISI distributions $\left(t_{(11)}=0.93 ; p>0.05\right)$ (Fig. $7 A$ ). Comparing pre- versus post-intra-BLA infusion epochs during PLC neuronal recordings revealed that intra-BLA WIN 55,212-2 significantly decreased average ISIs for both the $50 \mathrm{ng} / 0.5 \mu \mathrm{l}$ dose $\left(t_{(13)}=\right.$ 2.76; $p<0.05)$ and the $500 \mathrm{ng} / 0.5 \mu \mathrm{l}$ dose $\left(t_{(14)}=2.41 ; p<0.05\right)$ (Fig. $\left.7 A\right)$. In contrast, comparing pre- versus postintra-BLA infusion epochs during PLC neuronal recordings revealed that intraBLA AM251 significantly increased average ISI for both the $50 \mathrm{ng} / 0.5 \mu \mathrm{l}$ dose $\left(t_{(11)}=2.33 ; p<0.05\right)$ and the $500 \mathrm{ng} / 0.5$ $\mu \mathrm{l}$ dose $\left(t_{(14)}=2.23 ; p<0.05\right)$ (Fig. $\left.7 A\right)$. In Figure $7 B-G$, we present sample ISI distributions showing PLC neuronal ISI parameters before and after intra-BLA infusion of vehicle (Fig. $7 \mathrm{~B}, C$ ) or $500 \mathrm{ng} /$ $0.5 \mu$ l WIN 55,212-2 (Fig. $7 D, E$ ) or before and after intra-BLA infusion of $500 \mathrm{ng} / 0.5$ $\mu \mathrm{l}$ AM251 (Fig. 7F, G).

\section{Histological analysis: intra-BLA microinfusions and neuronal recording sites}

Histological analysis revealed the majority of microinjector placements and/or microelectrode recording tracks to be localized within the anatomical boundaries of the BLA or PLC as defined by Paxinos and Watson (1997). Rats found to have injecreceiving either 50 or $500 \mathrm{ng}$ doses of intra-BLA WIN 55,212-2 demonstrated significantly greater numbers of spikes per burst event $(p<0.05)$ (Fig. 6D). In Figure 6E-G, we present representative recording traces from PLC neurons, demonstrating characteristic pre- versus post-BLA infusion effects of vehicle (Fig. tor placements located outside the boundaries of the BLA $(n=4)$ or PLC $(n=5)$ were excluded from analysis. Figure $8 A$ shows a microphotograph of a representative injector cannula placement within the BLA. In Figure $8 B$, we show the same location at higher magnification, with anatomical demarcation of the BLA 
versus central nucleus of the amygdala. In Figure $8, C$ and $D$, we present summaries of representative bilateral intra-BLA microinjector placements for experimental groups receiving $2.5-50 \mathrm{ng} / 0.5 \mu \mathrm{l}$ intraBLA AM251 (Fig. 8C) or intra-BLA WIN 55,212-2 (5-50 ng/0.5 $\mu \mathrm{l}$ ) (Fig. 8D). Histological analysis of BLA stimulation and mPFC recording sites revealed BLA cannulae and PLC recording electrode sites localized within the anatomical boundaries of the BLA and PLC as defined by Paxinos and Watson (2005). Rats found to have placements outside these boundaries were excluded from analysis. Representative intra-PLC microinjector placements for experiments using intra-PLC muscimol infusions (see Materials and Methods) are schematically presented in Figure $8 E$. In Figure $8 F$, we present a representative microphotograph of a recording site localized to the PLC division of the $\mathrm{mPFC}$ and a representative microinfusion cannula placement localized to the BLA (Fig. 8G).

\section{Discussion}

Within the amygdala-prefrontal cortical circuit, CB1 receptor signaling can modulate neuronal plasticity and associative learning behavior (Azad et al., 2004; Laviolette and Grace, 2006a; Roche et al., 2007; Tan et al., 2010). The present results demonstrate that modulation of CB1 receptor transmission specifically within the BLA can strongly influence the encoding of emotionally salient associative memories via functional connectivity with the PLC and can influence neuronal firing frequency and burst activity in PLC neuronal subpopulations.

\section{Olfactory fear memory formation requires $\mathrm{CB} 1$ receptor transmission within the BLA}

Pharmacological inhibition of intra-BLA CB1 receptor transmission dose-dependently blocked the acquisition of olfactory fear memory, yet had no effect on the recall (expression) of previously acquired memories. This may suggest that once fear memory is acquired, neural circuits extrinsic to the BLA and/or non-CB1 receptor-mediated substrates may be involved in the expression of this memory. Given that mPFC neurons can encode fear memories via functional inputs from the BLA (Laviolette et al., 2005; Laviolette and Grace, 2006a), one possibility is that recently encoded memories are initially stored within the BLA through a CB1-dependent mechanism, but are transferred to the mPFC during the consolidation period between acquisition and recall testing. Interestingly, CB1 receptor blockade produces similar effects directly within the $\mathrm{MPFC}$ as intra-mPFC or systemic CB1 receptor blockade has been demonstrated to prevent the acquisition of fear memory both behaviorally and in single neurons of the mPFC (Laviolette and Grace, 2006a). The present results provide further evidence that $\mathrm{CB} 1$ receptormediated modulation of fear memory processing involves an integrative network comprising both the BLA and mPFC (Tan et al., 2010).

Various studies have reported that activation of $\mathrm{CB} 1$ receptors decrease GABAergic synaptic transmission in several brain
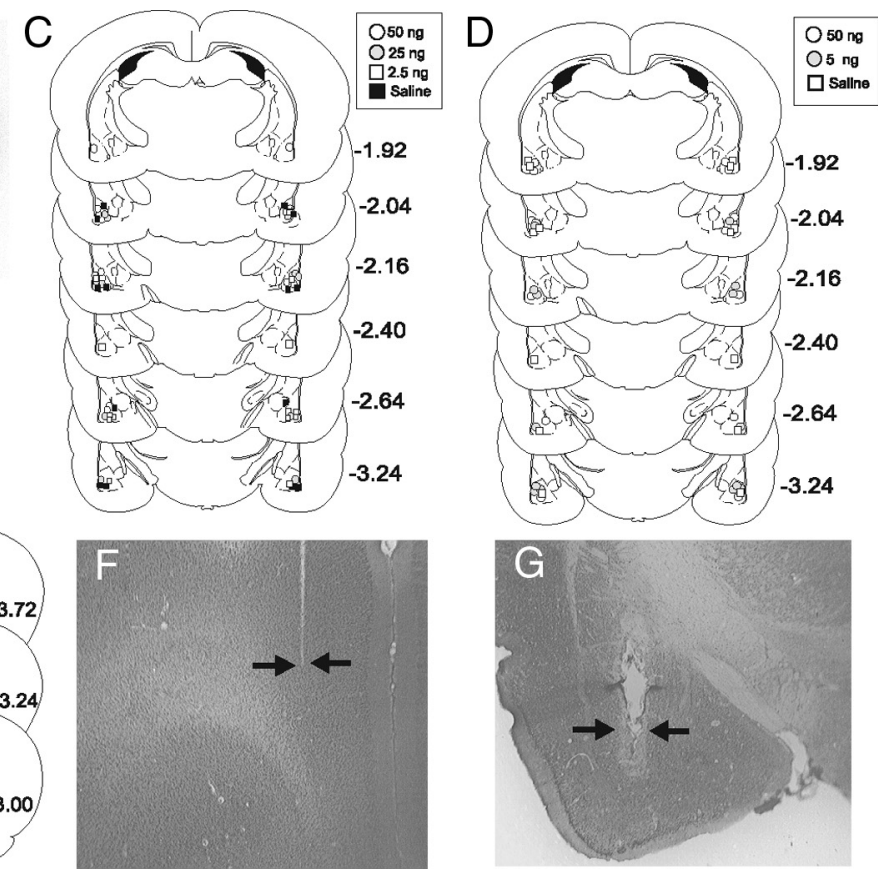

Histological analysis of intra-BLA or intra-PLC microinfusion, recording, and stimulation sites. $\boldsymbol{A}$, Microphotograph indicate electrode tip locations in both images.

regions important for emotional learning, including the nucleus accumbens (Hoffman and Lupica, 2001; Manzoni and Bockaert, 2001), hippocampus (Hoffman and Lupica, 2001), and amygdala (Azad et al., 2003, 2004). Within the BLA, high concentrations of CB1 receptors are found localized on inhibitory interneurons (McDonald and Mascagni, 2001). Thus, blockade of inhibitory CB1 receptors associated with this BLA neuronal population would be expected to increase local inhibitory feedback on BLA projection neurons, as suggested by other neuronal recording studies that have observed strong inhibition of BLA interneurons after application of CB1 receptor agonists (Azad et al., 2004; Pistis et al., 2004). Given that active output from the BLA to the mPFC is required for the encoding of emotionally salient information within neurons of the mPFC (Laviolette et al., 2005; Laviolette and Grace, 2006b), one possibility is that blockade of intra-BLA $\mathrm{CB} 1$ receptors localized on feedforward inhibitory interneurons within the BLA may increase net inhibition on BLA $>$ mPFC output neurons and thus block acquisition of fear memory, as demonstrated by the present behavioral results and further suggested by the finding that intra-BLA blockade of CB1 receptor transmission strongly inhibits spontaneous firing frequency and bursting activity within PLC neuronal subpopulations.

\section{Activation of BLA CB1 transmission potentiates fear memory} acquisition via connections with the PLC

We report that direct activation of $\mathrm{CB} 1$ receptor transmission or inhibition of endocannabinoid reuptake within the BLA can potentiate the acquisition of fear memory to normally subthreshold fear-conditioning stimuli. This effect involves the PLC as pharmacological inactivation of this region before $\mathrm{CB} 1$ receptor activation within the BLA prevented the memory-potentiating 
effects of intra-BLA WIN 55,212-2, without inducing nonspecific learning and/or memory impairments. Consistent with the present findings, Campolongo et al. (2009) have reported that intraBLA activation of CB1 receptors can potentiate the encoding of associative memory for inhibitory avoidance learning. Similarly, Roche et al. (2007) have reported that intra-BLA blockade of CB1 transmission with rimonabant can inhibit the formation of context-dependent fear memory and inhibit formalin-induced nociceptive responses. Thus, the current findings are consistent with previous findings demonstrating that CB1 receptor transmission specifically within the BLA can strongly influence the magnitude of emotional memory encoding. Our findings suggest that the PLC is a critical functional output for these behavioral effects and confirm previous reports demonstrating the integrative nature of CB1 receptor transmission within both the BLA and $\mathrm{mPFC}$ during the processing of associative emotional learning and memory, both at the systems level and at the level of the single neuron (Laviolette and Grace, 2006a; Tan et al., 2010). Previous studies examining the role of the $\mathrm{CB} 1$ receptor system in the modulation of emotional memory have reported that CB1 receptors are critical for the processing of extinction-related learning for previously acquired fear memories (Marsicano et al., 2002). Thus, one interesting possibility is that intra-BLA CB1 receptor modulation may influence the extinction rates of olfactory fear memories either within the BLA or via connections with the mPFC. Although future studies are required to address these issues, our present results suggest that cannabinoid transmission specifically within the BLA-mPFC circuit is essential also for modulating the acquisition of emotionally aversive memories through functional interactions with the PLC.

\section{Cannabinoid transmission within the BLA modulates neuronal activity patterns in the PLC}

In the present study, activation or inhibition of intra-BLA CB1 receptor transmission produced mixed effects on spontaneous neuronal activity patterns within the PLC. Across all PLC neurons sampled, a plurality demonstrated a decrease in spontaneous firing frequency and bursting activity after intra-BLA inhibition of CB1 receptor transmission. In contrast, a plurality of sampled PLC neurons demonstrated increased firing and bursting activity after intra-BLA CB1 receptor activation. Nevertheless, we observed smaller subpopulations of PLC neurons that demonstrated the opposite response patterns after intra-BLA modulation of CB1 transmission and subpopulations of neurons that demonstrated no response after intra-BLA CB1 receptor modulation. The complex response patterns observed in the PLC are perhaps not surprising, given that the BLA and $\mathrm{mPFC}$ share bidirectional functional connections that can modulate neuronal activity and emotional memory encoding within either region (Rosenkranz and Grace, 2003; Laviolette et al., 2005; Tan et al., 2010). Interestingly, only BLA-responsive neurons within the mPFC show encoding and expression of associative emotional memory (Laviolette et al., 2005; Laviolette and Grace, 2006a), suggesting that specific subpopulations of mPFC neurons under the modulatory influence of ascending BLA inputs are involved directly in the acquisition and/or expression of fear memory.

Previous in vivo electrophysiological studies suggest that $\sim 60 \%$ of mPFC neurons are inhibited by electrical BLA stimulation (Floresco and Tse, 2007) and that BLA $>$ mPFC glutamatergic projections show a complex anatomical distribution with some terminals directly synapsing onto pyramidal neurons and others onto parvalbumin-positive GABAergic interneurons (Gabbot et al., 2006). This evidence is consistent with the present results wherein $\mathrm{CB} 1$ modulation within the BLA produced mixed effects on mPFC neuronal activity. Furthermore, the present findings suggest that $\mathrm{CB} 1$ receptor modulation of the BLA $>$ mPFC pathway targets specific neuronal subpopulations within the PLC that can modulate the strength of associative emotional memory encoding. The precise mechanisms by which BLA inputs may modulate PLC neuronal activity are not presently known. However, given the known ability of intra-BLA CB1 receptor modulation to influence excitatory BLA $>$ PLC projections, one possibility is that intra-BLA AM251 may block inhibitory $\mathrm{CB} 1$ receptors located on feedforward inhibitory inputs to BLA > PLC projection neurons producing increased inhibition to these BLA outputs and blocking the encoding of associative emotional memory via the BLA $>$ PLC pathway. In contrast, intra-BLA CB1 receptor activation would produce the opposite effect, by potentially activating inhibitory $\mathrm{CB} 1$ receptors localized to feedforward inhibitory interneurons within the BLA and thereby removing net inhibition on BLA outputs to the PLC and thus amplifying neuronal encoding of emotionally salient associative memory via the BLA $>$ PLC projection pathway. In addition, given the reciprocal relationship between the PLC and BLA, an alternative possibility is that $\mathrm{CB} 1$ modulation of BLA outputs to the PLC may in turn modulate the activity of PLC neurons projecting back to the BLA and possibly modulate fear memory formation directly within the BLA via descending mPFC $>$ BLA projections. Such a complex arrangement may be further suggested by our findings that modulation of CB1 receptors within the BLA (either activation or inhibition) produced mixed excitatory or inhibitory responses in separate PLC neuronal populations. However, given that neurons within the mPFC encode and express fear memory via CS+-specific increases in firing frequency and bursting levels (Laviolette et al., 2005; Laviolette and Grace, 2006a), the present results suggest that activation or inhibition of BLA CB1 transmission can amplify or block emotional memory encoding concomitant with differential effects on mPFC neuronal firing frequency and bursting activity.

\section{Conclusions}

The present results demonstrate that $\mathrm{CB} 1$ receptor transmission within the BLA is involved importantly in modulating the formation of fear memories via functional connections with the PLC division of the mPFC. Our results further suggest a critical role for the PLC in these effects as inactivation of the PLC prevented the potentiation of fear memory induced by intra-BLA CB1 receptor modulation. In addition, direct modulation of intra-BLA $\mathrm{CB} 1$ receptor transmission using behaviorally effective doses of either $\mathrm{CB} 1$ receptor agonists or antagonists can produce bidirectional effects on spontaneous neuronal activity parameters within neuronal subpopulations localized to the PLC, suggesting an integrative functional relationship between the BLA and PLC during the formation of fear memories.

\section{References}

Aggleton JP (2000) The amygdala: a functional analysis, Ed 2. New York: Oxford UP.

Antoniadis EA, McDonald RJ (1999) Discriminative fear conditioning to context expressed by multiple measures of fear in the rat. Behav Brain Res 101:1-13.

Azad SC, Eder M, Marsicano G, Lutz B, Zieglgänsberger W, Rammes G (2003) Activation of the cannabinoid receptor type 1 decreases glutamatergic and GABAergic synaptic transmission in the lateral amygdala of the mouse. Learn Mem 10:116-128.

Azad SC, Monory K, Marsicano G, Cravatt BF, Lutz B, Zieglgänsberger W, Rammes G (2004) Circuitry for associative plasticity in the amygdala involves endocannabinoid signaling. J Neurosci 24:9953-9961. 
Bangalore SS, Prasad KM, Montrose DM, Goradia DD, Diwadkar VA, Keshavan MS (2008) Cannabis use and brain structural alterations in first episode schizophrenia: a region of interest, voxel based morphometric study. Schizophr Res 99:1-6.

Barbieri R, Quirk MC, Frank LM, Wilson MA, Brown EN (2001) Construction and analysis of non-Poisson stimulus response models of neural spiking activity. J Neurosci Methods 105:25-37.

Campolongo P, Roozendaal B, Trezza V, Hauer D, Schelling G, McGaugh JL, Cuomo V (2009) Endocannabinoids in the rat basolateral amygdala enhance memory consolidation and enable glucocorticoid modulation of memory. Proc Natl Acad Sci U S A 106:4888-4893.

Cohen M, Solowij N, Carr V (2008) Cannabis, cannabinoids and schizophrenia: integration of the evidence. Aust N Z J Psychiatry 42:357-368.

Floresco SB, Tse MT (2007) Dopaminergic regulation of inhibitory and excitatory transmission in the basolateral amygdala-prefrontal cortical pathway. J Neurosci 27:2045-2057.

Gabbott PL, Warner TA, Busby SJ (2006) Amygdala input monosynaptically innervates parvalbumin immunoreactive local circuit neurons in rat medial prefrontal cortex. Neuroscience 139:1039-1048.

Herkenham M, Lynn AB, Little MD, Johnson MR, Melvin LS, de Costa BR, Rice KC (1990) Cannabinoid receptor localization in brain. Proc Natl Acad Sci U S A 87:1932-1936.

Hoffman AF, Lupica CR (2001) Direct actions of cannabinoids on synaptic transmission in the nucleus accumbens: a comparison with opioids. J Neurophysiol 85:72-83.

Katona I, Rancz EA, Acsady L, Ledent C, Mackie K, Hajos N, Freund TF (2001) Distribution of CB1 receptors in the amygdala and their role in the control of GABAergic transmission. J Neurosci 21:9506-9518.

Lauzon NM, Bishop SF, Laviolette SR (2009) Dopamine D1 versus D4 receptors differentially modulate salient versus nonsalient emotional information in the medial prefrontal cortex. J Neurosci 29:4836-4845.

Laviolette SR, Grace AA (2006a) Cannabinoids dramatically potentiate emotional learning plasticity in neurons of the medial prefrontal cortex through basolateral amygdala. J Neurosci 26:6458-6468.

Laviolette SR, Grace AA (2006b) The roles of cannabinoid and dopamine receptor systems in neural emotional learning circuits: implications for schizophrenia and addiction. Cell Mol Life Sci 63:1597-1613.

Laviolette SR, Lipski WJ, Grace AA (2005) A subpopulation of neurons in the medial prefrontal cortex encodes emotional learning through burst and frequency codes through a dopamine D4 receptor-dependent basolateral amygdala input. J Neurosci 25:6066-6075.

Manzoni OJ, Bockaert J (2001) Cannabinoids inhibit GABAergic synaptic transmission in mice nucleus accumbens. Eur J Pharmacol 412:R3-R5.

Marsicano G, Wotjak CT, Azad SC, Bisogno T, Rammes G, Cascio MG, Hermann H, Tang J, Hofmann C, Zieglgänsberger W, Di Marzo V, Lutz B (2002) The endogenous cannabinoid systems controls extinction of aversive memories. Nature 418:530-534

McDonald AJ, Mascagni F (2001) Localization of the CB1 type cannabinoid receptor in the rat basolateral amygdala: high concentrations in a subpopulation of cholecystokinin-containing interneurons. Neuroscience 107: 641-652.

Paxinos G, Watson C (1997) The rat brain in stereotaxic coordinates, Ed 3 . San Diego: Academic.

Pistis M, Perra S, Pillolla G, Melis M, Gessa GL, Muntoni AL (2004) Cannabinoids modulate neuronal firing in the rat basolateral amygdala: evidence for CB1 and non-CB1-mediated actions. Neuropharmacology 46:115-125.

Roche M, O'Connor E, Diskin C, Finn DP (2007) The effects of CB1 receptor antagonism in the right basolateral amygdala on conditioned fear and associated analgesia in rats. Eur J Neurosci 26:2643-2653.

Rosenkranz JA, Grace AA (2002) Cellular mechanisms of infralimbic and prelimbic prefrontal cortical inhibition and dopaminergic modulation of basolateral amygdala neurons in vivo. J Neurosci 22:324-337.

Rosenkranz JA, Moore H, Grace AA (2003) The prefrontal cortex regulates lateral amygdala neuronal plasticity and responses to previously conditioned stimuli. J Neurosci 23:11054-11064.

Schneider M (2008) Puberty as a highly vulnerable developmental period for the consequences of cannabis exposure. Addict Biol 13:253-263.

Tan H, Lauzon NM, Bishop SF, Bechard MA, Laviolette SR (2010) Integrated cannabinoid CB1 transmission within the amygdala-prefrontal cortical pathway modulates neuronal plasticity and emotional memory encoding. Cereb Cortex 20:1486-1496.

Tsou K, Brown S, Sañudo-Peña MC, Mackie K, Walker JM (1998) Immunohistochemical distribution of cannabinoid CB1 receptors in the rat central nervous system. Neuroscience 83:393-411. 